\title{
Differentiating Indexation in Dutch Pension Funds
}

\author{
Roel M. W. J. Beetsma • Alessandro Bucciol
}

Published online: 24 May 2011

(c) The Author(s) 2011. This article is published with open access at Springerlink.com

\begin{abstract}
Funded social security programs are particularly vulnerable to economic and financial market shocks. As a consequence of the recent crisis, a large fraction of the Dutch pension funds had to submit restoration plans for the recovery of their buffers. Such plans will have to rely primarily on a mix of reduced benefit indexation and increased pension contributions. Hence, a discussion has emerged whether indexation should be differentiated across the various groups of participants in a pension fund. We investigate this issue numerically, developing an applied many-generation small open-economy OLG model with heterogeneous agents. The pension system consists of a first-pillar PAYG component and a second pillar with a pension fund. In our stochastic simulations, we hit the economy with a variety of unexpected demographic, economic and financial shocks. We compare uniform indexation of pension
\end{abstract}

The authors thank two anonymous referees, Rob Alessie, Stefan Staubli and the participants of the 2009 CeRP conference on "Saving for Old Age in a Financial Turmoil" held in Turin and the 2009 WDA/Scala workshop on "Pension Challenges and the Financial Crisis". Financial support from Netspar and Mn Services is gratefully acknowledged. The usual disclaimers apply.

\section{R. M. W. J. Beetsma}

University of Amsterdam, Netspar, Mn Services, Tinbergen Institute, CEPR and CESifo, Amsterdam, The Netherlands

R. M. W. J. Beetsma ( $\varangle)$

Department of Economics, University of Amsterdam, Valckenierstraat 65-67, Amsterdam 1018 XE, The Netherlands

e-mail: r.m.w.j.beetsma@uva.nl

\section{A. Bucciol}

University of Verona, University of Amsterdam, and Netspar, Verona, Italy

A. Bucciol

Department of Economics, University of Verona, Viale Università 4, Verona 37129, Italy

e-mail: alessandro.bucciol@univr.it 
rights across all fund participants with alternatives such as status-contingent indexation in which pensions are protected against price inflation. While the aggregate welfare consequences are small, group-specific consequences are more substantial with the workers and future born losing and retirees benefitting from a shift away from uniform indexation. The exception is a scheme which links indexation directly to the fund's asset performance. Under this scheme the retired benefit without other groups losing. The welfare effects are primarily the result of systematic welfare redistributions rather than of shifts in the benefits of risk sharing. Contribution rates always have to rise substantially from their initial levels to maintain the system's sustainability. An increase in the retirement age that leaves existing pension rights untouched does little to avoid this rise with its adverse labour market consequences.

Keywords Indexation - Funded pensions - Welfare effects · Pension buffers . Stochastic simulations

\section{JEL Classification $\mathrm{H} 55 \cdot \mathrm{I} 38 \cdot \mathrm{C} 61$}

\section{Introduction}

Funded social security systems are vulnerable to financial market shocks as the consequences of the recent financial crisis have shown. These consequences have also alerted both policymakers and academics to the question how risks should be shared among the participants in funded pension systems. It is well known from the literature that non-funded social security can raise welfare through the intergenerational sharing of income risks (Enders and Lapan 1982; Merton 1983). However, there has been less research on how pension funds can affect welfare through intergenerational risk sharing. The literature suggests that income uncertainty is just weakly correlated with the uncertainty on asset returns (Heaton and Lucas 2000). This makes pension funds a priori suitable vehicles for risk sharing between workers and retirees. This is also the case for the second pension pillar in the Netherlands, which to a certain extent can be characterised as a defined-benefit (DB) system. In this paper we will explore how the indexation of pension rights to price and wage inflation can be adjusted to improve the operation of the system.

The overall Dutch pension system is largely based on an unfunded pay-as-yougo (PAYG) first pillar and a funded second pillar. ${ }^{1}$ The system shares features with systems like those in, for example, the U.S., ${ }^{2}$ Germany and Switzerland. The second pillar is unusually large, though, because it is roughly the size of the first pillar and it is expected to grow further in relative terms. Through their contributions to sectoral or company pension funds workers build up rights to a future nominal pension. Both contribution and accumulation rates are identical across a fund's participants. Hence,

\footnotetext{
1 The system also features a third pillar, which is based on voluntary (tax-facilitated) savings mostly through insurance companies. This pillar is of relatively minor importance, though.

2 Nowadays, most pension funds in the U.S. are of a defined contribution (DC) type, but pension funds in the public sector are generally of a DB type. Hence, the Dutch second pillar resembles more closely the situation in the U.S. public sector.
} 
those on higher incomes contribute more and accumulate more rights. Second pillar benefits are of a defined-benefit nature in the sense that accumulated rights guarantee the holder a nominally-fixed benefit in euros as of retirement until death. Accumulated rights are usually once a year heightened up to compensate for the past rate of price inflation, with the aim of protecting the purchasing power of the pension, or wage inflation, such that the pension benefit tracks the general increase in welfare. However, indexation is not required by law and the board of the pension fund may index by less than full or not even at all if this is deemed necessary to maintain a healthy funding ratio as measured by the ratio of pension assets over liabilities.

The pension fund is a vehicle for intergenerational risk sharing. For example, financial market developments affect the size of the pension buffers and may lead to a change in the contribution rate and/or the indexation rate. This way, younger generations share in the financial market risks that tend to be mostly concentrated among the older people. By linking indexation to wages, retirees share in the productivity risk which is mostly born by the workers (Bohn 2006). Uncertainties in life expectancy can be buffered by both changes in indexation and pension premia.

When the funding ratio falls below a given "long-term" threshold (roughly 125\% for a fund with average investment risk), the fund has to submit a "long-term" (15 year) restoration plan to the supervisor, the Dutch central bank (DNB), to return to above this threshold, while when the funding ratio falls below $105 \%$, a situation called "underfunding", it has to submit a "short-term" (3 or 5 year) plan to eliminate the underfunding. Funds have to rely on a mix of reduced indexation, higher contributions and, in case these instruments provide insufficient restoration power, partially writing off existing pension rights. The latter instrument is considered the last resort and supervision is aimed at avoiding this in all but very exceptional circumstances.

This paper focuses on changes in indexation as the main instrument for the stabilisation of pension buffers, because contribution rates in the Netherlands are generally thought to have reached their "natural" maximum. There is a growing discussion whether the policy parameters should be differentiated across the various groups of participants in a pension fund. Specifically, Hurst and Willen (2007) find it typically welfare improving to have pension contributions increase with the worker's age. Indeed, in the Netherlands much of the discussion focuses on differentiating contribution or accumulation rates over cohorts in order to reduce the effective redistribution in the system from younger to older cohorts. A related discussion concerns the differentiation of indexation across the various groups of participants in a fund. By law (Article 58 of the Dutch Pension Law), indexation is uniform across the group of workers and it is uniform across the group of all former workers and retirees together. The desirability of uniform indexation is increasingly being called into question. However, there has only been limited analysis of what would be the best way to differentiate indexation across groups of fund participants. Exceptions are Ponds (2008) and Molenaar and Ponds (2009), who explore a combination of indexation to the pension portfolio return and to nominal wage growth, where the relative weight attached to the first component is decreasing with age. In this paper we also analyse differentiated indexation across participants. Differences with Ponds (2008) and Molenaar and Ponds (2009) concern the types of differentiation we consider, the specification of the shock menu, the 
microfoundations underlying our model and our use of an explicit welfare comparison among the alternative arrangements that we study.

Because accumulated pension rights are increasing over a person's working life, retirees and those close to retirement will be hurt most by a uniform reduction in indexation. Moreover, these groups are left with little or no flexibility to make up for any loss of indexation by working more, while, in addition, a given loss of purchasing power has to be absorbed by a consumption reduction over a relatively short remaining lifetime. Hence, these groups are at particular risk under policies that resort to changing the indexation rate in order to keep pension buffers stable. Because financial market risks are a major source of fluctuation in pension buffers, pension income of the elderly is particularly sensitive to financial market shocks even though the younger generations would be best placed to bear this source of risk, also given the imperfect correlation between the return on human wealth and that on financial wealth. In fact, the seminal analysis in Bodie et al. (1992) shows that the share of total (human plus financial) wealth invested in equity should be constant over one's lifetime, implying that shocks in stock prices have identical proportional effects on consumption at all ages. This would be an argument to shift a disproportionate part of the indexation risk to younger workers, at least to the extent that this risk is primarily linked to the financial market performance of the pension fund's asset portfolio.

We explore a number of alternatives to uniform indexation across the participants. One alternative is to have "status-contingent" indexation, in which the retired always receive exactly enough indexation to compensate for price inflation, while the indexation rate of the entire group of workers moves uniformly in response to changes in the pension buffer. This alternative is permitted under the Dutch pension law. We also consider more complicated alternatives to uniform indexation that are currently not allowed by Dutch pension law. One is to reduce changes in the indexation rate with age, the idea being that older people hold more rights on average and, hence, are hurt more severely by uncertainty in the indexation rate. A particularly interesting alternative is that of what we refer to as "market-contingent" indexation, in which indexation is a weighted average of the return on the pension fund's asset portfolio and the uniform indexation schedule, with the relative weight attached to the portfolio return gradually declining with age to zero at retirement. This scheme comes close to the schemes proposed in Ponds (2008) and Molenaar and Ponds (2009).

We develop an applied small-open economy overlapping generations model with annual cohorts of heterogeneous agents and a pension system that incorporates the main features of the Dutch system. In our stochastic simulations, calibrated to the situation in the Netherlands, we hit the economy with a variety of unexpected shocks. These may be broadly classified into three categories: demographic uncertainty (the size of newborn generations and survival probabilities that determine life expectancy), economic uncertainty (productivity growth and the inflation rate) and financial uncertainty (bond and equity returns and yield curve).

At the aggregate level, as measured by the equivalent variation for all groups together, the only schedule that outperforms uniform indexation is market-contingent indexation. The average difference with uniform indexation in terms of compensating initial resources tends to be relatively small, though, and is always less than $0.5 \%$ of the initial resources of individuals. At the group level the effects are larger. Initial 
retirees benefit from a switch away from uniform indexation, while the workers and future born are net payers for the switch. Only in the case of market-contingent indexation are those latter groups unaffected. Most of the benefit to the initially retired and the payment by the others is purely redistributional. Only a relatively small part of the welfare effects is the result of a difference in the effectiveness of risk sharing. We also investigate the robustness of these results by varying within reasonable bounds the initial pension buffer, the assumed equity premium and the volatility of the equity returns. However, the results remain essentially unaltered in qualitative terms. Under all indexation schemes, second-pillar contribution rates have to increase substantially from initial levels to maintain the fund's sustainability in the wake of increasing longevity. An increase in the retirement age that leaves existing pension rights untouched does little to avoid this increase and leaves our basic results essentially unaltered.

The paper is organised as follows. Section 2 provides a brief discussion of the literature on risk sharing within social security systems. Section 3 lays out the main elements of the model. Section 4 describes the policy rule and the various indexation schedules, while Sect. 5 provides details about the calibration and simulation setup. Section 6 reports the results of the stochastic simulations for the various indexation schedules under the benchmark calibration. This section also presents a robustness analysis of our results. Section 7 concludes the main text. The "Appendix" gives details on the estimation and the calibration of the shocks. Finally, the online appendix, available at http://www1.fee.uva.nl/mint/beetsma.shtm, provides further details on the model, the policy rule followed by the pension funds and the outcomes of some variations on our benchmark.

\section{Literature Review}

Bodie et al. (1992) use a life-cycle model with the possibility to invest in two assets (risk-free and equity). They start assuming a non-stochastic wage and consider the case of a constant level of labour supply optimally chosen at the start of one's life and the case of a flexible labour supply that can respond to the performance of their investment portfolio. In particular, a bad stock market performance induces individuals to increase their labour supply. More importantly, the opportunity to ex post vary the labour supply leads individuals to invest with more risk. The main results are the following. The optimal amount invested in equity is proportional to total wealth, i.e. the sum of human and financial wealth. The initial amount of investment in equity is likely to substantially exceed financial wealth at the beginning of one's life. Moreover, it is higher under flexible labour supply. Further, the share of financial wealth invested in equity is decreasing over one's working life as human capital gets depleted and becomes constant upon retirement. Bodie et al. (1992) also consider stochastic wages. The processes for the wage rate and the stock price are assumed to be perfectly correlated. The consequence is that human capital can be seen as equivalent to the combination of an investment in equity and an investment in a risk-free asset. Hence, through their human capital individuals already possess an implicit investment in equity and, hence, the explicit equity investment is the difference between the total desired exposure to equity risk and the implicit exposure already present. 
In the view of Teulings and De Vries (2006) the role of pension funds is to take intertemporal consumption decisions on behalf of participants who find it difficult to take such decisions for themselves and to allow for intra-temporal sharing of longevity risks. They build a model in which individuals supply until their exogenous retirement age a given amount of labour against a deterministic wage. Further, they die at a given, known age and they can invest in risk-free bonds and risky equity. The results on the optimal investment allocation are essentially identical to those in Bodie et al. (1992). Gains from intergenerational risk-sharing can be obtained when new pension fund participants absorb upon entry part of the fund's gains or losses made in recent years before the entry. This way new entrants invest over a longer period of their life in equity, thereby further diversifying their risk exposure. This type of risk sharing is effectively applied in the Dutch pension system, as new entrants share in the under- or overfunding of their fund at the moment of entry, thereby sharing in the past investment performance of the fund.

Cui et al. (2011) compare intergenerational risk sharing in funded pension schemes with individually-optimal investment schemes. The funded pensions feature DB elements. If assets minus liabilities are positive (negative) then contributions may be reduced (raised) and pension benefits may be raised (reduced). Three types of risksharing rules are considered in the case of a mismatch. Under the first rule only contributions are changed and only workers share in the risks. Under the second rule, only benefits are changed and only the retired share in the risk, while under the final rule both contributions and benefits are adjusted. This is the preferred regime, because under this regime the largest number of generations share in the risks. Under this scheme investment in risky assets is largest, while the adjustment parameters in contributions and benefits are small implying that mismatch vanishes only gradually.

Bohn (2001) compares the welfare effects of population ageing and demographic shocks between defined-benefit and defined-contribution pension schemes in a twoperiod overlapping generations model meant to represent the U.S. economy. He argues that neither of these schemes is efficient, because it is optimal that all risks are shared by all generations, including the retired.

Our framework differs in a number of ways from that in the other contributions discussed here. Different from Bohn (2001), our framework is a many-generations small-open economy. He incorporates only demographic shocks, while in Teulings and De Vries (2006) there is only uncertainty about the return on the investment portfolio. Also in Bodie et al. (1992) there is only one source of uncertainty. Even when wages are stochastic, they are perfectly correlated with equity returns. We allow for more sources of risk than these other contributions. Specifically, in contrast to Bodie et al. (1992), in our setup productivity risks and stock market returns are imperfect correlated. This is important, because under this assumption a pension fund acquires a useful role in reallocating productivity risk from workers to retirees and reallocating stock market risk from retirees to workers. Apart from Bohn (2001), we deviate from the other contributions by incorporating a rising life expectancy. Also in contrast to the other contributions we allow for intragenerational inequality and we explicitly address indexation policy, which plays a crucial role in DB funded pension systems. The additional complications that we introduce in this paper also force us to make some simplications in other directions. In particular, we will assume that the labour supply 
and the composition of individual investment portfolios are exogenous. ${ }^{3}$ This latter assumption has the advantage that we simulate a model with realistic portfolio allocations. $^{4}$

\section{The Model}

We present an overlapping generations model in which individuals may not only differ by birth year, but also by skill level. Given an individual's age, the skill level determines his income. Our framework also incorporates a description of a two-pillar social security system intended to model the main features of the Dutch pension system.

The first pillar is a PAYG arrangement organised by the government. It sets an identical contribution rate for all workers such that this pillar is balanced on a periodby-period basis. To every retiree it pays out a flat benefit, which is a given fraction of average income, implying that the contribution rate is adjusted in response to shocks to average income. Hence, the first pillar is a highly redistributive part of the Dutch social security system. The second pillar consists of private pension funds that provide defined-benefit nominal pensions. Individuals with income above the so-called franchise contribute to their fund and build up rights to a second-pillar pension benefit.

Both the intragenerational (skill) heterogeneity and the first pillar are essential elements of our model. The latter element is important despite the fact that the focus of our analysis is on the second pillar. In our analysis, we not only want to explore the qualitative effects of alternative indexation schedules, but we also want to assess the quantitative consequences of alternative schedules. A realistic effort in this direction is most safely achieved by incorporating the most relevant elements into the model. More importantly, while we will be interested in the aggregate welfare effects of switching away from uniform indexation, we will be far more concerned with the group-specific consequences. Due to the way the first pillar has been set up in the Netherlands, for an individual of given age, the magnitude of the welfare consequences differs substantially by skill level. Hence, it is precisely the combination of intragenerational heterogeneity and the presence of our first pillar that is key to some of the main results of the paper. In particular, given the franchise for the second pillar, for low-skilled individuals the first pillar is the only or main source of income in retirement. As a result, changes in the way second pillar pensions are indexed can only have limited welfare consequences for these individuals.

\subsection{Cohorts and Demography}

A period in the model corresponds to one year. We assume that individuals enter the labour force on their 25th birthday and we denote by the age of a cohort the amount of time since entry into the labour force. An individual's age is indicated by the index

\footnotetext{
${ }^{3}$ Related works that allow for endogenous labour supply in funded pension systems are Bucciol and Beetsma (2010) and Bonenkamp and Westerhout (2010).

${ }^{4}$ Investment allocations determined through optimisation lead to portfolios with unrealistically high shares of equity. This is problematic for simulations aimed at realistically quantifying the consequences of alternative policy scenarios.
} 
$j=0,1, \ldots, D$, where $D$ is the maximum number of years a person can live after entry into the labour force. Hence, there are $D$ overlapping cohorts each period. Each period there is an exogenous age-dependent probability that an individual will die. An individual who has entered the labour force at the start of period $t-(j-1)=t-j+1$ has an exogenous marginal probability $\psi_{j, t-j+1} \in[0,1]$ of reaching age $j$ at the end of period $t$ conditional on having reached age $j-1$ at the end of period $t-1$. This probability is stochastic and exhibits an upward trend, thereby also causing an upward trend in the average age of the population. Further, the cohort of newborns (i.e. new entrants into the labour force) in period $t$ is $1+n_{t}$ times larger than the cohort of newborns one period earlier, where $n_{t}$ is also stochastic.

\subsection{Skill Groups and the Income Process}

Each individual belongs to some skill group $i$, with $i=1, \ldots, I$, and remains in this skill group during its entire working life. A higher value of $i$ corresponds to a higher skill level. The division into skill groups is such that all groups contain an equal number of individuals. Given the macroeconomic circumstances, an individual's income is uniquely determined by the combination of its age and skill level. In other words, all the individuals of a given age in the same skill-group earn the same hourly wage.

Individuals work for $R$ years after which they retire until their death. During their working life, they receive a labour income $y_{i, j, t}$ given by:

$$
y_{i, j, t}=e_{i} s_{j} z_{t}
$$

where $e_{i}, i=1, \ldots, I$ is the efficiency index for skill group $i, s_{j}, j=1, \ldots, R$ is a seniority index to allow income for a given skill level to vary with age, and $z_{t}$ is the exogenous process

$$
z_{t}=\left(1+g_{t}\right) z_{t-1}
$$

where $g_{t}$ is its exogenous, stochastic nominal growth rate and $z_{1}=1$.

\subsection{Social Security and Accidental Bequests}

\subsubsection{The First Pillar of the Social Security System}

Each period, an individual of working age pays a mandatory contribution $p_{i, j, t}^{F}$ to the first pillar of the social security system. This contribution depends on its income $y_{i, j, t}$ relative to certain thresholds $\delta^{l} y_{t}$ and $\delta^{u} y_{t}$ :

$$
p_{i, j, t}^{F}=\left\{\begin{array}{ll}
0 & \text { if } y_{i, j, t}<\delta^{l} y_{t} \\
\theta_{t}^{F}\left(y_{i, j, t}-\delta^{l} y_{t}\right) & \text { if } y_{i, j, t} \in\left[\delta^{l} y_{t}, \delta^{u} y_{t}\right] \\
\theta_{t}^{F}\left(\delta^{u} y_{t}-\delta^{l} y_{t}\right) & \text { if } y_{i, j, t}>\delta^{u} y_{t}
\end{array}\right\}, \quad j \leq R,
$$


where $\delta^{l}, \delta^{u}$ and $\theta_{t}^{F}$ are policy parameters and $y_{t}=\sum_{j=1}^{R} \frac{N_{j, t}}{I} \sum_{i=1}^{I} y_{i, j, t} / \sum_{j=1}^{R} N_{j, t}$ is average income. In period $t$ the benefit received by an individual retiree is a fraction $\rho^{F}$ of average income:

$$
b_{t}^{F}=\rho^{F} y_{t}
$$

Each period the contribution rate $\theta_{t}^{F}$ is adjusted such that aggregate contributions into the first pillar equal aggregate first-pillar benefits. Notice that someone on an income lower than $\delta^{l} y_{t}$ pays no contribution, but still receives the same benefit as someone with a high income.

\subsubsection{The Second Pillar of the Social Security System}

Each period, a worker pays a mandatory contribution $p_{i, j, t}^{S}$ to the second pillar if its income exceeds the franchise income level $\lambda y_{t}$, where parameter $\lambda$ denotes the franchise as a share of average income. Specifically,

$$
p_{i, j, t}^{S}=\theta_{t}^{S} \max \left\{0, y_{i, j, t}-\lambda y_{t}\right\}, \quad j \leq R,
$$

where $\theta_{t}^{S}$ is a policy parameter, which we assume to be capped at a maximum value of $\theta^{S, \max }>0$. The contract underlying a second-pillar pension arrangement in the Netherlands generally imposes a cap on the contribution rate and we include this feature into the model. As we shall describe below, the contribution rate will depend on the financial situation of the pension fund, as described by its funding ratio.

An individual from skill group $i$ of cohort $j$ receives a second-pillar pension benefit linked to his entire wage history given by:

$$
b_{i, j, t}^{S}=M_{i, j, t}, \quad j>R,
$$

where $M_{i, j, t}$ is the "stock of nominal pension rights" accumulated by the end of period $t$. It is the annual benefit in euros that the retiree receives each year during retirement, as long as this number is not revised through indexation or a reduction by writing off existing rights. ${ }^{5}$ Variable $M_{i, j, t}$ is a stock variable that increases with each additional year of work the individual has provided. At the end of period $t$ it is given by:

$$
M_{i, j, t}=\left\{\begin{array}{cc}
\left(1-m_{t}\right)\left\{\begin{array}{c}
\left(1+\omega_{i, j, t}\right) M_{i, j-1, t-1} \\
+\mu \max \left\{0, y_{i, j, t}-\lambda y_{t}\right\}
\end{array}\right\}, & j \leq R \\
\left(1-m_{t}\right)\left(1+\omega_{i, j, t}\right) M_{i, j-1, t-1}, & j>R
\end{array}\right\}
$$

where parameter $\mu$ is the annual accrual rate and parameter $\omega_{i, j, t}$ is the rate of indexation of nominal rights. It will depend on the financial position of the pension fund,

\footnotetext{
5 For example, someone of age 35 who has accumulated 2,000 euros of nominal rights, would, if he were to stop working now and in the absence of indexation or a reduction, receive 2,000 euros each year as of his 65 th birthday.
} 
as we will detail below, and it is also allowed to be potentially cohort- and skill-group specific. Further, $m_{t}>0$ is a proportional reduction in nominal rights that may be applied when the funding ratio is so low that restoration is no longer possible using other instruments, while $m_{t}<0$ when earlier reductions are undone. We assume that $m_{t}>0$ only when $\omega_{i, j, t}=0$. Each individual enters the labour market with zero nominal claims $\left(M_{i, 0, t-j}=0\right.$ for any $i$ and $\left.t\right)$. In contrast to the first-pillar pension benefit, the second-pillar benefit depends on both the cohort and skill level of the individual.

Given the accrual rate $\mu$ and franchise share $\lambda$, the choice of the fund's policy parameters $\theta_{t}^{S}, \omega_{i, j, t}$ and $m_{t}$ depends on the level of the nominal funding ratio

$$
F_{t}=\frac{A_{t}}{L_{t}}
$$

where $A_{t}$ and $L_{t}$ are the values of the fund's assets, respectively liabilities. At the end of period $t$ the fund's assets are aggregate contributions in period $t$ minus total benefits paid out in period $t$ plus the assets at the end of period $t-1$ grossed up by their return in the financial markets:

$$
A_{t}=\left(\sum_{j=1}^{R} \frac{N_{j, t}}{I} \sum_{i=1}^{I} p_{i, j, t}^{S}-\sum_{j=R+1}^{D} \frac{N_{j, t}}{I} \sum_{i=1}^{I} b_{i, j, t}^{S}\right)+\left(1+r_{t}^{f}\right) A_{t-1}
$$

where

$$
1+r_{t}^{f}=\left(1-z^{e}\right)\left(1+r_{t}^{l b}\right)+z^{e}\left(1+r_{t}^{e}\right)
$$

where $r_{t}^{f}$ is the average nominal return on the fund's assets in period $t-1, r_{t}^{l b}$ is the return on long-term bonds and $r_{t}^{e}$ the return on equities. All asset returns are exogenously determined on the international financial markets, in line with the situation of the Netherlands being a small open economy operating under perfect capital mobility. ${ }^{6}$ Further, an exogenous share $z^{e}$ of the fund's value is invested in equities and the remainder in long-term nominal bonds. Actual data for Dutch pension funds show a rather stable composition over the years, which may point to pension funds aiming at stable targets for the various asset categories. For this reason we can assume that $z^{e}$ is constant.

The long-term bonds held by the pension fund always have a 10-year maturity. Therefore, at the end of each year bonds of 9-year maturity are sold for new 10-year bonds. The online appendix shows that

\footnotetext{
6 Determining those returns endogenously would require us to turn our model into a general equilibrium setup and explicitly model the supply of the assets by the government and firms. This would be beyond the scope of our paper and would distract the attention from our main results.
} 


$$
r_{t}^{l b}=\frac{\left(1+r_{10, t-1}^{b}\right)^{10}}{\left(1+r_{9, t}^{b}\right)^{9}}-1
$$

where $r_{10, t-1}^{b}\left(r_{9, t}^{b}\right)$ is the yield on a 10-year (9-year) zero coupon bond in year $t-1$ (year $t$ ).

The fund's liabilities are the sum of the present values of current and future rights already accumulated by the cohorts currently alive:

$$
L_{t}=\sum_{j=1}^{D} \frac{N_{j, t}}{I} \sum_{i=1}^{I} L_{i, j, t},
$$

where $L_{i, j, t}$ is the liability to the cohort of age $j$ and skill level $i$, which is computed as the discounted sum of the projected future nominal benefits based on the current stock of nominal rights. Discounting takes place against a term structure of annual nominal interest rates $\left\{r_{k, t}\right\}_{k=1}^{D}$. Hence,

$$
L_{i, j, t}=\left\{\begin{array}{ll}
E_{t}\left[\sum_{l=R+1-j}^{D-j}\left(\prod_{k=1}^{l} \psi_{j+k, t-j+1} \frac{1}{\left(1+r_{l, t}\right)} M_{i, j, t}\right],\right. & \text { if } j \leq R \\
E_{t}\left[\sum_{l=0}^{D-j}\left(\prod_{k=1}^{l} \psi_{j+k, t-j+1}\right) \frac{1}{\left(1+r_{l, t}\right)^{l}} M_{i, j, t}\right], & \text { if } j>R
\end{array}\right\} .
$$

When $j \leq R$, we discount all future benefits to the current year $t$, but of course they will only be paid out once individuals have retired. Crucially, in the Netherlands the computation of the liabilities excludes any future indexation. Hence, pension funds that aim at maintaining the purchasing power of the accumulated rights need to maintain a funding ratio that is substantially above $100 \%$.

\subsubsection{Accidental Bequests}

The only role of accidental bequests in the model is to ensure that resources do not "disappear" because people die. The government collects all the financial assets from those who die and redistributes them through equal transfers to all those still alive.

\subsection{The Individual Decision Problem}

Each period individuals choose nominal consumption $c_{i, j, t}$. The state variables are assets $a_{i, j, t}$ and the income process $z_{t}$. The individual's value function is:

$$
V_{i, j, t}\left(a_{i, j, t}, z_{t}\right)=\max _{c_{i, j, t}}\left\{u\left(\widetilde{c}_{i, j, t}\right)+\beta \psi_{j+1, t-j+1} E_{t}\left[V_{i, j+1, t+1}\left(a_{i, j+1, t+1}, z_{t+1}\right)\right]\right\},
$$


subject to

$$
a_{i, j+1, t+1}=\left(1+r_{j, t+1}\right)\left(a_{i, j, t}-c_{i, j, t}+\tilde{y}_{i, j, t}\right),
$$

where the period utility function $u\left(\widetilde{c}_{i, j, t}\right)$ is given by

$$
u\left(\widetilde{c}_{i, j, t}\right)=\frac{1}{1-\gamma} \widetilde{c}_{i, j, t}^{1-\gamma},
$$

where $\gamma$ is the coefficient of relative risk aversion and $\widetilde{c}_{i, j, t}$ is real consumption,

$$
\widetilde{c}_{i, j, t}=\frac{c_{i, j, t}}{\prod_{s=1}^{t}\left(1+\pi_{s}\right)},
$$

where $\pi_{t}$ is the rate of price inflation in period $t$. Further, $\tilde{y}_{i, j, t}$ is total income net of contributions:

$$
\tilde{y}_{i, j, t}=\left\{\begin{array}{ll}
y_{i, j, t}+h_{t}-p_{i, j, t}^{F}-p_{i, j, t}^{S}, & \text { if } j \leq R \\
b_{t}^{F}+b_{i, j, t}^{S}+h_{t}, & \text { if } j>R
\end{array}\right\},
$$

where $h_{t}$ is the accidental bequest, while the portfolio rate of return depends on the age-specific share invested in equities, $x_{j}$ :

$$
1+r_{j, t+1}=\left(1-x_{j}\right)\left(1+r_{t+1}^{s b}\right)+x_{j}\left(1+r_{t+1}^{e}\right)
$$

where a share $\left(1-x_{j}\right)$ is invested in one-year bonds against a return $r_{t+1}^{s b}$.

\subsection{The Shocks}

The estimation of the shock processes is described in detail in the "Appendix". Here, we provide a brief description. There are only aggregate shocks in the model. The menu of shocks consists of demographic shocks, shocks to the income growth rate and the inflation rate, which together determine productivity shocks, and financial market shocks. All these shocks are collected in the vector $\zeta_{t}=$ $\left[\epsilon_{t}^{n}, \epsilon_{t}^{\psi}, \epsilon_{t}^{g}, \epsilon_{t}^{\pi}, \epsilon_{t}^{e}, \epsilon_{t}^{s b}, \epsilon_{2, t}^{b}, \ldots, \epsilon_{D, t}^{b}\right]$ with elements

- $\epsilon_{t}^{n}$ : shock to the newborn cohort growth rate, $n_{t}$.

- $\epsilon_{t}^{\psi}$ : shock to the set of survival probabilities, $\left\{\psi_{j, t-j+1}\right\}_{j=1}^{D}$.

- $\epsilon_{t}^{g}$ : shock to the nominal income growth rate, $g_{t}$.

- $\epsilon_{t}^{\pi}$ : shock to the inflation rate, $\pi_{t}$.

- $\epsilon_{t}^{e}$ : shock to the nominal equity return, $r_{t}^{e}$.

- $\epsilon_{t}^{s b}:$ shock to the 1-year "short-term" bond return, $r_{t}^{s b}$.

- $\epsilon_{k, t}^{b}, k=2, \ldots, D$ : shock to the nominal bond return at maturity $k, r_{k, t}^{b}$. 
All these shocks affect the funding ratio, while only demographic shocks affect the first-pillar of the pension system. In response to the shocks the parameters of the pension system may need to be adjusted to restore the balance in the first pillar and to maintain the sustainability of the second pillar.

Each demographic shock is distributed independently of all the other shocks. The growth rate $n_{t}$ of the newborn cohort depends on deterministic and random components:

$$
n_{t}=n+\epsilon_{t}^{n}
$$

where $n$ is the mean and $\epsilon_{t}^{n}$ the innovation at time $t$, which follows an $\mathrm{AR}(1)$ process. The survival probabilities evolve according to a Lee and Carter (1992) model. Further, we allow the shocks to the inflation rate, nominal income growth, the one-year bond return and the equity return to be correlated with each other and over time. These variables feature the following multivariate process:

$$
\left(\begin{array}{l}
\pi_{t} \\
g_{t} \\
r_{t}^{s b} \\
r_{t}^{e}
\end{array}\right)=\left(\begin{array}{l}
\pi \\
g \\
r^{s b} \\
r^{e}
\end{array}\right)+\left(\begin{array}{l}
\epsilon_{t}^{\pi} \\
\epsilon_{t}^{g} \\
\epsilon_{t}^{s b} \\
\epsilon_{t}^{e}
\end{array}\right)
$$

with means $\left(\pi, g, r^{s b}, r^{e}\right)^{\prime}$ and innovations $\left(\epsilon_{t}^{\pi}, \epsilon_{t}^{g}, \epsilon_{t}^{s b}, \epsilon_{t}^{e}\right)^{\prime}$ for year $t$ that follow a VAR(1) process,

$$
\left(\begin{array}{l}
\epsilon_{t}^{\pi} \\
\epsilon_{t}^{g} \\
\epsilon_{t}^{s b} \\
\epsilon_{t}^{e}
\end{array}\right)=\mathbf{B}\left(\begin{array}{l}
\epsilon_{t-1}^{\pi} \\
\epsilon_{t-1}^{g} \\
\epsilon_{t-1}^{s b} \\
\epsilon_{t-1}^{e}
\end{array}\right)+\left(\begin{array}{l}
\eta_{t}^{\pi} \\
\eta_{t}^{g} \\
\eta_{t}^{s b} \\
\eta_{t}^{e}
\end{array}\right), \quad\left(\begin{array}{l}
\eta_{t}^{\pi} \\
\eta_{t}^{g} \\
\eta_{t}^{s b} \\
\eta_{t}^{e}
\end{array}\right) \sim N\left(\mathbf{0}, \Sigma_{f}\right)
$$

Hence, our shocks consist of a deterministic component, which is a linear combination of previous-year shocks, and a purely random component, given by realizations from i.i.d. innovations.

The yield curve is constructed by setting the return $r_{1, t}^{b}$ at the one-year maturity at $r_{t}^{s b}$ and the returns at higher maturities $k \geq 2$ equal to the sum of the one-year return $r_{t}^{s b}$ plus the excess of the return at maturity $k$ relative to the one-year return, $\widetilde{r}_{k, t}^{b}$, which is simulated on the basis of an estimated vector autoregressive distributed lag (VADL) process with lag 1 for $\widetilde{r}_{k, t}^{b}, k=2, \ldots, D$.

\subsection{Welfare Comparisons Between Policy Scenarios}

We compare welfare between the two scenarios $A$ (our benchmark scenario) and $B$ (the alternative) at the start of period $t=1$ for individuals alive at that moment and at the start of their first year of life for individuals that are born later. The individual welfare comparison is based on the equivalent variation $E V_{i, j, t}$, which for skill group 
$i$ of cohort $j$ we define as the amount of wealth that should be added in scenario $A$ to obtain the same utility as in scenario $B$. That is, for those alive at the start of $t=1$, we define $E V_{i, j, 1}$ by the equation

$$
V_{i, j, 1}^{A}\left(a_{i, j, 1}+E V_{i, j, 1}, z_{1}\right)=V_{i, j, 1}^{B},
$$

where $\left(a_{i, j, 1}+E V_{i, j, 1}, z_{1}\right)$ are the arguments of the value function, that is the level of assets plus the equivalent variation and the level of the income process at the start of $t=1$, while for those born at the start of $t \geq 2$, we define $E V_{i, 1, t}$ by the equation

$$
V_{i, 1, t}^{A}\left(a_{i, 1, t}+E V_{i, 1, t}, z_{t}\right)=V_{i, 1, t}^{B},
$$

where $a_{i, 1, t}+E V_{i, 1, t}$ is the initial level of assets at birth plus the equivalent variation and $z_{t}$ is the level of the income process at the start of $t$. The equivalent variations for various groups can be added up to produce an aggregate welfare comparison at $t=1$ :

$$
\begin{aligned}
E V= & \left(\sum_{j=1}^{D} N_{j, 1} \frac{1}{I} \sum_{i=1}^{I} E V_{i, j, 1}\right) \\
& +\left(\sum_{k=2}^{251} \frac{N_{1, k}}{((1+g)(1+n))^{k-1}} \frac{1}{I} \sum_{i=1}^{I} E V_{i, 1, k}\right) .
\end{aligned}
$$

This expression sums the equivalent variations of all individuals alive at time $t=1$ and the equivalent variations at birth $(j=1)$ of all future-born individuals discounted at the rate $(1+g)(1+n)-1$. We choose this particular discount rate, because $\frac{1}{I} \sum_{i=1}^{I} E V_{i, 1, k}$ grows on average at the same rate $g$ as nominal income and each new generation $N_{1, k}$ in period $k$ is on average $(1+n)$ times the size of the previous young generation. Hence, the weight of future-born generations in the overall measure $E V$ is made comparable to the weight of the currently-alive generations.

As an alternative aggregate measure we take the percentage of those alive at $t=1$ in favour of the alternative policy:

$$
\operatorname{PER}=\sum_{j=1}^{D} N_{j, 1} \frac{1}{I} \sum_{i=1}^{I} \mathbf{1}_{\left\{V_{i, j, 1}^{B}>V_{i, j, 1}^{A}\right\}}
$$

where $1_{\{.\}}$is an indicator function that equals unity if the condition within the curly parentheses holds, and 0 otherwise.

\section{The Policy Rule}

The government automatically adjusts the contribution rate $\theta_{t}^{F} \in(0,1)$ to maintain a balanced first pillar of the pension system. On average, this contribution rate increases 
over the years along with the ageing of the population. More policy instruments are available to affect the funding ratio of the second pillar. There are three key parameters, of which the period $t+1$ values are determined on the basis of the funding ratio in period $t, F_{t}$ : the contribution rate $\theta_{t+1}^{S} \in\left[0, \theta^{S, \max }\right]$, an indexation parameter $\kappa_{t+1} \geq 0$ and, as a last resort, a reduction $\left(m_{t+1}>0\right)$ or restoration $\left(m_{t+1}<0\right)$ of the nominal pension rights. The board of the pension fund selects the contribution rate and the indexation parameter, but can only reduce nominal rights under special circumstances, as described below.

Policymakers aim at achieving a target indexation rate $\kappa$ to average nominal wage growth $g$, which in the sequel we set at the sum of $\pi=2 \%$ average annual price inflation and $1 \%$ average annual productivity growth. Hence, $g=3 \%$. Because average price inflation is $2 / 3$ of average nominal wage growth, long-run protection of pension rights against price inflation would require setting $\kappa=2 / 3$, which we shall do from now on. Depending on the current financial situation of the pension fund, as measured by the funding ratio, the actual average (across the population) indexation rate $\kappa_{t}$ to actual nominal wage growth $g_{t}$ may differ from the target indexation rate. The actual individual indexation rate $\omega_{i, j, t}$ of pension rights of an individual with skill level $i$ and age $j$ in period $t$ is given by:

$$
\omega_{i, j, t}=g \kappa+\left[\max \left\{0, g_{t} \kappa_{t}\right\}-g \kappa\right] f(i, j)
$$

where $g_{t} \kappa_{t}-g \kappa$ measures the deviation of actual average indexation $g_{t} \kappa_{t}$ from target indexation $g \kappa$. If actual average indexation is relatively high, such that $g_{t} \kappa_{t}>g \kappa$, and $f(i, j)>0$, then actual individual indexation exceeds target indexation. The function $f(i, j)$ allows the pension fund to allocate more of less of the deviation of actual average indexation $g_{t} \kappa_{t}$ from target indexation $g \kappa$ to specific skill and age groups. The idea is that some groups may have less capacity to bear the risk associated with indexation, while other groups could have more capacity in this regard. Obviously, if the fund in this way reduces indexation uncertainty for some groups, then for other groups uncertainty is raised. Hence, we may have $f(i, j)<1$ for some groups and $f(i, j)>1$ for other groups.

We describe now the link between the funding ratio and the actual average indexation rate. We define three threshold values for the funding ratio, $\xi^{l}=1.05<\xi^{m}<$ $\xi^{u}=1.50$, where $\xi^{m}=1.25$. $^{7}$ When the funding ratio $F_{t}$ exceeds $\xi^{m}$, then, after restoring possible earlier cuts in nominal rights, the fund sets the contribution rate $\theta_{t+1}^{S}$ at its initial level $\theta_{1}^{S}$ and the actual average indexation rate for the next period to $\kappa_{t+1}=\frac{2}{3}+\frac{1}{3} \frac{F_{t}-\xi^{m}}{\xi^{u}-\xi^{m}}$. Hence, indexation in $t+1$ increases linearly in $F_{t}$ and is complete (equal to 1 ) at $\xi^{u}$. Notice that for $F_{t}$ approaching $\xi^{m}$ from above, $\kappa_{t+1}$ reaches its long-run target level $\frac{2}{3}$. Notice also that the indexation rate exceeds unity when the funding ratio exceeds $\xi^{u}$. This way the funding ratio is stabilised from above.

\footnotetext{
7 The lower threshold is the official one imposed by the supervisors in the Netherlands in order to protect the nominal pension rights. The upper threshold corresponds to the one at which many funds start providing full indexation to nominal wages, hence the one at which the value of the pension rights grows in line with the overall welfare level.
} 
As mandated by the Dutch Pension Law, when the funding ratio falls below $\xi^{m}$, but remains above $\xi^{l}$, a long-term restoration plan is started, while when it falls below $\xi^{l}$, a short-term restoration plan is started. The latter situation is termed "underfunding". The long-term restoration plan requires a restoration of the funding ratio to at least $\xi^{m}$ in at most $K^{l}=15$ years (ignoring possible future shocks), while the short-term restoration plan requires restoration to at least $\xi^{l}$ in at most $K^{s}=5$ years (ignoring possible future shocks). Hence, policy is aimed at keeping the funding ratio above $\xi^{m}$. Specifically, within each year of the restoration plan indexation is set as follows:

$$
\kappa_{t+1}=\left\{\begin{array}{ll}
0, & \text { if } F_{t} \leq \xi^{l} \\
\frac{2}{3} \frac{F_{t}-\xi^{l}}{\xi^{m}-\xi^{l}}, & \text { if } F_{t} \in\left(\xi^{l}, \xi^{m}\right]
\end{array} .\right.
$$

Notice that, if $F_{t}$ approaches $\xi^{m}$ from below, $\kappa_{t+1}$ also reaches its long-run target level $\frac{2}{3}$ and, hence, there is no discontinuity in the scheme for $\kappa_{t+1}$ at $F_{t}=\xi^{m}$. Based on the scheme (17), the projected funding ratio is computed (assuming further shocks are absent) and compared with its target $\left(\xi^{l}\right.$ or $\left.\xi^{m}\right)$ prescribed by the restoration plan. If necessary, the contribution rate $\theta_{t}^{S}$ is raised up to at most its maximum $\theta^{S \text {, max }}$. Hence, there is a direct link between the contribution rate and the performance of the pension fund's asset portfolio as well as the indexation ambition $g \kappa$ of the fund. A bad performance of the fund's assets or a higher indexation ambition make it more likely for the funding ratio to fall below the thresholds at which restoration plans need to be started. Conform Dutch Pension Law, when there is underfunding $\left(F_{t}<\xi^{l}\right)$ and the adjustments in the indexation parameter and the contribution rate are jointly insufficient, nominal rights are scaled back by whatever amount is necessary to eliminate the underfunding within the allowed restoration period. In the case of a long-term restoration plan, nominal rights remain untouched. A detailed description of the operation of the restoration plans is found in the online appendix.

We consider a baseline of "uniform" indexation, in which actual indexation is the same for all the fund participants, and four different schemes in which actual indexation is made contingent. Under "status-contingent" indexation, retirees always receive a certain indexation rate (corresponding to full price indexation on average), while all the workers receive an identical, but uncertain indexation rate. Under "age-contingent" indexation, the uncertainty about indexation falls with age. Under "incomecontingent" indexation, the uncertainty about indexation is smaller when the present value of second-pillar pension income is larger relative to the present value of income from all sources. Finally, under "market-contingent" indexation, indexation is partially linked to the market performance of the fund's asset portfolio, with the link becoming smaller as one gets closer to retirement.

\section{(1) Baseline: uniform indexation}

In any given year, indexation is identical for all the individuals. That is,

$$
f(i, j)=1
$$

We take this as the benchmark case. It is also the most common situation in the Netherlands. 


\section{(2) Status-contingent indexation}

For retirees the indexation rate is constant over time, whatever is the size of the funding ratio. By contrast, all the workers are subject to identical uncertainty about the indexation rate. Specially,

$$
f(i, j)= \begin{cases}\alpha^{s} & j \leq R \\ 0 & j>R\end{cases}
$$

where $\alpha^{s}>0$. This is the simplest possible variation on the benchmark of uniform indexation. The rationale for this scheme is that retirees have relatively little room for responding to shocks, because their expected remaining life expectancy is relatively low. Fixing the indexation rate may reduce their consumption uncertainty.

\section{(3) Age-contingent indexation}

All individuals are subject to uncertainty about actual indexation relative to target indexation. However, the uncertainty shrinks with age. The rationale for this scheme is analogous to that for the previous scheme: the older a person gets, the shorter its expected time to death and the larger will be the effect of a given shock on its yearly consumption flow. Specifically, we impose that

$$
f(i, j)=\alpha^{a}(D-j)
$$

where $\alpha^{a}>0$.

\section{(4) Income-contingent indexation}

Indexation is subject to uncertainty for all individuals, but uncertainty is negatively related to the present value of second-pillar pension income relative to the present value of income from all sources (labour, accidental bequests and first- and secondpillar pension benefits) at time $t=1 .^{8}$ The idea is that for individuals, for whom income from the second pillar of the pension system is relatively important, should face less uncertainty about the indexation of this source of income than individuals for whom the second pillar is a relatively minor income source. In particular, for an age $j$ and skill group $i$ individual, the present value of second-pillar pension income (henceforth termed "second-pillar pension wealth") $W_{i, j, 1}^{S}$ is given by:

$$
W_{i, j, 1}^{S}=E_{1}\left[\sum_{l=\max \{0, R+1-j\}}^{D-j} \frac{1}{\psi_{j, 1-j+1}}\left(\prod_{k=0}^{l} \psi_{j+k, 1-j+1}\right) \frac{1}{\left(1+r_{l}^{b}\right)^{l}} b_{i, j+l, 1+l}^{S}\right] .
$$

Notice that this present value takes into account the uncertainty around death age (through the survival probabilities), and discounts future benefits using bond yield returns, as is common practice in this literature (see, e.g., Bodie et al. 1992; Pelizzon

\footnotetext{
8 We take the values at the beginning of the simulation to avoid the circularity problem of having indexation rates that depend on the rescaling function $f(i, j)$, which in turn depends on indexation rates. The initial indexation rate is known and is based on the initial funding ratio according to (17).
} 
and Weber 2009). To avoid complicating matters too much we discount expected future benefits against the average yield curve $r_{l}^{b}, l=1, \ldots, D$ (see the online appendix). We define "first-pillar pension wealth" $W_{i, j, 1}^{F}$ analogously as:

$$
W_{i, j, 1}^{F}=E_{1}\left[\sum_{l=\max \{0, R+1-j\}}^{D-j} \frac{1}{\psi_{j, 1-j+1}}\left(\prod_{k=0}^{l} \psi_{j+k, 1-j+1}\right) \frac{1}{\left(1+r_{l}^{b}\right)^{l}} b_{i, j+l, 1+l}^{F}\right]
$$

and "labour income wealth" $W_{i, j, 1}^{Y}$ as the present value of future labour income realisations (plus accidental bequests and minus pension contributions):

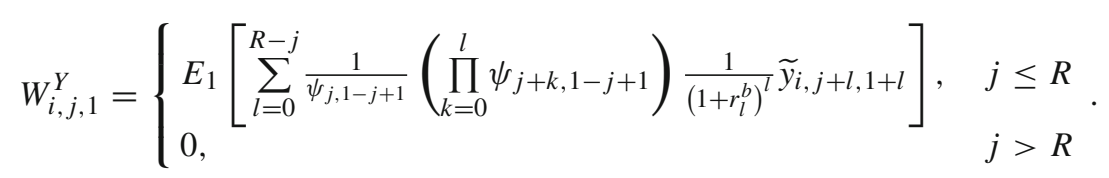

We may define "human wealth" as the sum of labour income wealth, first-pillar pension wealth and second-pillar pension wealth. Finally, we define $R_{i, j, 1}^{S}$ as the ratio between second-pillar wealth and human wealth:

$$
R_{i, j, 1}^{S}=\frac{W_{i, j, 1}^{S}}{W_{i, j, 1}^{Y}+W_{i, j, 1}^{F}+W_{i, j, 1}^{S}} .
$$

The rescaling function under income-contingent indexation is:

$$
f(i, j)=\alpha^{i}\left(\max _{i, j}\left\{R_{i, j, 1}^{S}\right\}-R_{i, j, 1}^{S}\right)
$$

where $\alpha^{i}>0$. The idea is that those with a relatively larger share of their human wealth in the second pension pillar face less uncertainty about the deviation of actual indexation of their second-pillar benefits from its target level.

In the above schedules, the rescaling function $f(i, j)$ depends only on one parameter that we calibrate so as to produce a funding ratio similar to that under uniform indexation. In particular, the parameter is always calibrated in such a way that applying the rescaling function does not change the total amount of nominal rights:

$$
\sum_{j=1}^{D} \frac{N_{j, 1}}{I} \sum_{i=1}^{I} M_{i, j, 1} f(i, j)=\sum_{j=1}^{D} \frac{N_{j, 1}}{I} \sum_{i=1}^{I} M_{i, j, 1}
$$

Figure 1 shows the profile of the indexation schedules. In general, contingentindexation policies reduce the difference between actual and target indexation rates for older households. For income-contingent indexation, the deviations are also smaller for richer households. 


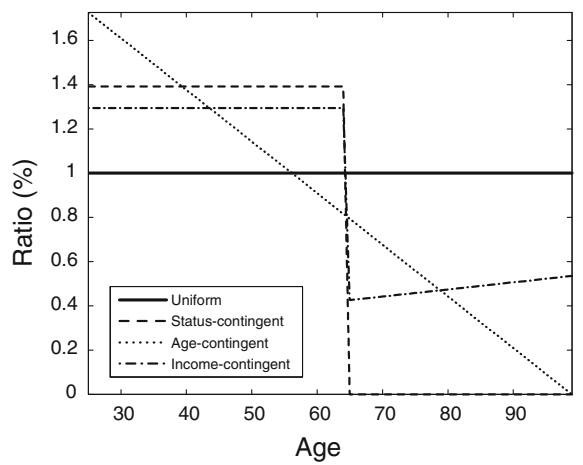

(a) All schemes

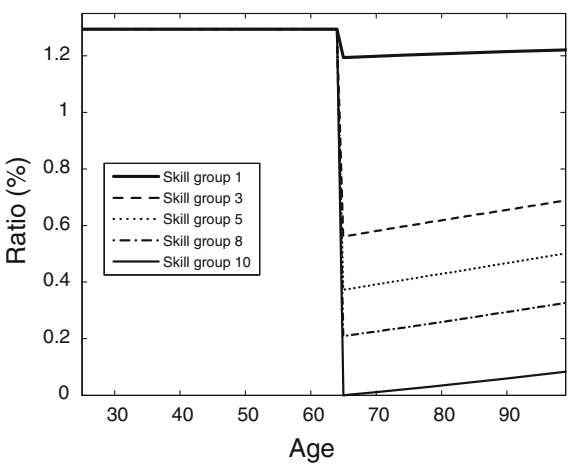

(b) Income-contingent

Fig. 1 Rescaling functions. Notes The figure depicts for the various indexation schemes the relationship $f(i, j)$ as a function of age $j$ and skill-level $i$. The skill level is only relevant for income-contingent indexation. For this latter case, in panel $a$. we take the average scheme across the various skill levels. This scheme is very close to that of skill group 5

\section{(5) Market-contingent indexation}

Our fifth, and final, indexation scheme, which we refer to as "market-contingent" indexation, is rather different from the previous ones. Under this scheme, which is inspired by Ponds (2008) and Molenaar and Ponds (2009), indexation is as follows linked to the performance of the fund's asset portfolio:

$$
\omega_{i, j, t}=\left\{\begin{array}{ll}
\max \left\{0, \frac{j}{R} g_{t} \kappa_{t}+\left(1-\frac{j}{R}\right)\left(r_{t}^{f}-b\right)\right\}, & \text { if } j \leq R \\
g_{t} \kappa_{t}, & \text { if } j>R
\end{array}\right\},
$$

where we set $b=r^{f}-g \kappa$ so as to make the average contribution of this component of the schedule equal to $g \kappa$. As it turns out, the fund's portfolio performance $r_{t}^{f}$ will be more uncertain than the nominal wage indexation component $g_{t} \kappa_{t}$. Hence, also this schedule features falling indexation uncertainty as working life progresses. As under status-contingent indexation, there is zero indexation uncertainty during retirement. A distinctive feature of this schedule is that it establishes a direct link between the performance of the asset portfolio and the increase in liabilities through indexation. Hence, compared with the other schedules, one may expect a reduction in the risk of mismatch between assets and liabilities.

\section{Calibration and Simulation Details}

\subsection{Benchmark Calibration}

The economically active life of an individual starts at his 25 th birthday. He then works for $R=40$ years. Individuals live for at most $D=75$ years after entry into the labour force. We set the discount factor at $\beta=0.96$, a rather common number in the macroeconomic literature (e.g., see Imrohoroglu 1989; Krebs 2007), and the coefficient 
of relative risk aversion at $\gamma=3$, which accords quite well with the assumed risk aversion in much of the macroeconomic literature (see, e.g., Imrohoroglu et al. 2003) as well as estimates at the individual level (for example, Gertner 1993 and Beetsma and Schotman 2001). The efficiency index $\left\{e_{i}\right\}_{i=1}^{I}$ is based on the income deciles for the Netherlands for the year 2000 reported by the World Income Inequality Database (WIID, version 2.0c, May 2008). We normalise the index such that it has an average value of unity. The seniority index $\left\{s_{j}\right\}_{j=1}^{I}$ uses the average of Hansen (1993) estimation of median wage rates by age group. We take the average between males and females and interpolate the data using the spline method. The composition of individual investment portfolios is exogenously given and the shares $x_{j}, j=1, \ldots, D$ invested in equity are based on the figures reported by age in Table 9 of Alessie et al. (2001).

The social security parameters are based on those for the Dutch pension system. The maximum income assessable for contributions to the first pillar is 3, 850.40 euros per month in 2008, as reported by the Dutch Tax Office ("Belastingdienst"). Therefore, we set $\delta^{u}=1.10$, which is roughly equal to $3,850.40 * 12 / 42,403$, where 42,403 euros is our imputation for the economy's average income for $2008 .{ }^{9}$ Further, we set $\delta^{l}=0.4685$, so as to generate an initial contribution rate of $\theta_{1}^{F}=12.77 \%$ that is identical to the initial second-pillar contribution rate, $\theta_{1}^{F}=\theta_{1}^{S}$. The latter we calculate on the assumption that aggregate contributions and benefits at time 1 are equal in the absence of shocks. This value of $\theta_{1}^{S}$ is close to the actual value in the Netherlands. We cap $\theta_{t}^{S}$ at $\theta^{S, \max }=25 \%$. Finally, we set the benefit scale factor at $\rho^{F}=0.2435$.

We assume that the pension fund always invests half of its portfolio in equities, hence we set $z^{e}=0.50$ for any level of the funding ratio $F_{t}$. This corresponds roughly to the balance sheet average for Dutch pension funds over the past 10 years (DNB 2009). Because realised returns on bond and equity investments will generally differ, at the end of each period the fund reshuffles its portfolio such that at the start of the next period the equity share is again $z^{e}=0.50$. We set the pension accrual rate $\mu$ to $2 \%$ and the franchise parameter $\lambda$ to $0.381 .^{10}$

We calibrate $\rho^{F}$ and $\lambda$ so as to generate realistic replacement rates at retirement date that are on average equal to $30.40 \%$ for the first pillar and $37.60 \%$ for the second pillar. The first-pillar replacement rate is decreasing in the skill level and ranges from an average of $12.06 \%$ for the highest skill group to $63.33 \%$ for the lowest skill group. By contrast, the second-pillar replacement rate is higher for more skilled groups and ranges from an average of $3.78 \%$ to an average of $56.64 \%$. The overall replacement rate of the two pillars together is higher for more skilled groups, but differences are small and the average replacement rates range from 67.11 to $68.70 \%$.

The deterministic component of the growth rate of the newborn cohort, $n=$ $0.2063 \%$, is the average annual growth rate based on the estimation of an order-

\footnotetext{
9 Eurostat's most recent figure on average Dutch income refers to the year 2005. The same source also provides minimum income until the year 2008. Exploiting the correlation between average and minimum income, we run an OLS regression of average income on minimum income. As a result, we predict the average income for year 2008 to be 42,403 euros.

10 The maximum accrual rate that is fiscally facilitated in the Netherlands is $2.25 \%$ for pension arrangements based on the average wage over the working life and $2 \%$ for arrangements linked to the final wage.
} 
Table 1 Benchmark calibration of the exogenous parameters

\begin{tabular}{lll}
\hline Symbol & Description & Calibration \\
\hline General setting & & \\
$D$ & Number of cohorts & 75 \\
$R$ & Number of working cohorts & 40 \\
$\beta$ & Discount factor & 0.96 \\
$\gamma$ & Relative risk aversion parameter & 3 \\
$\left\{e_{i}\right\}_{i=1}^{I}$ & Efficiency index & WIID (2008) \\
$\left\{s_{j}\right\}_{j=1}^{R}$ & Seniority index & Hansen (1993) \\
First pillar pension parameters & \\
$\left\{\delta^{l}, \delta^{u}\right\}$ & Income thresholds in the contribution formula & $\{0.469,1.10\}$ \\
$\rho^{F}$ & Benefit scale factor & 0.2435 \\
Second pillar pension parameters & \\
$z^{e}$ & Equity share in fund portfolio & 0.5 \\
$\left\{K^{S}, K^{L}\right\}$ & Restoration periods in years & $\{5,15\}$ \\
$\mu$ & Second-pillar pension accrual rate & 0.02 \\
$\lambda$ & Franchise share & 0.381 \\
$F_{1}$ & Initial funding ratio & 1.15 \\
$\theta^{S, \text { max }}$ & Upper bound on contribution rate & 0.25 \\
Annual averages of the random variables & \\
$\pi$ & Inflation rate & $2 \%$ \\
$g$ & Nominal income growth rate & $3 \%$ \\
$r^{\text {sb }}$ & One-year nominal bond return & $3 \%$ \\
$r^{e}$ & Equity return & $6 \%$ \\
\hline
\end{tabular}

one moving-average model of the annual number of births in the Netherlands over the period 1906-2005 (source is the Human Mortality Database 2009). Our calibration of the survival probabilities is based on the estimation of a Lee and Carter (1992) model using Dutch period survival probabilities. ${ }^{11}$ The combination of survival probabilities and birth rates determines the size of each cohort. The starting value of the old-age dependency ratio (i.e., the ratio of retirees over workers) is $20.99 \%$, in line with the OECD (2009) figure for the Netherlands in 2005.

The averages we calibrate for price inflation, nominal income growth and the bond and equity returns are reported in the final four lines of Table 1 . We loosely follow the literature (see, e.g., Brennan and Xia 2002; Van Ewijk et al. 2006) and, as already mentioned, set average annual inflation at $\pi=2 \%$ and average annual nominal income growth at $g=3 \%$. This corresponds to average real productivity growth of $1 \%$ per annum. We set the average 1 -year bond yield at $r^{s b}=3 \%$. Finally, we set the average

11 With these probabilities, the average population age is initially set to 48.21 years and the remaining life expectancy to 33.54 years, as opposed to 33.23 years for a 48 -year old in 2005 according to the actual data (see Human Mortality Database 2009). 
annual equity return at $r^{e}=6 \%$ in order to generate a funding ratio that is stable over time in the absence of shocks and policy parameter changes.

\subsection{Simulation Details}

We draw $Q=1,000$ sequences of vectors of unexpected shocks over $2 D-1+250=$ 399 years, simulated from the joint distribution of all the shocks. Our welfare calculation is based on the economy as of the $D$ th year in the simulation. Hence, we track only the welfare of the cohorts that are alive in that year, implying that those that die earlier are ignored, and we track the welfare of cohorts born later, the latest one dying in the final period of the simulation. In other words, the total number of years of one simulation run equals the time distance between the birth of the oldest cohort that we track and the complete extinction of the last unborn cohort that we track. In each period there are $D$ overlapping generations. For convenience, in the simulation we relabel the $D$ th year as $t=1$. The first $D-1$ years of our simulation, the "initialisation phase", are needed to generate a distribution of the assets across the various groups at the start of $t=1$.

In each simulation run, we set the trends in newborn growth rates and in survival probabilities to zero after $t=40$, thereby stopping the ageing process after $t=40$, although the shocks to both processes remain. Hence, also mortality rates at any given age are no longer on a falling trend. We stop the ageing process, because we want to avoid an ever-growing population as a result of the ageing process and the associated complications with the simulations. ${ }^{12}$

To allow for a proper comparison of the various indexation schedules, we use the same simulated shock series for each schedule both during the initialisation phase and during the remainder of the simulation run. At the start of the initialisation phase the pension rights of all the individuals are set to zero and during this phase they accumulate pension rights according to (7), while indexation is always uniform and applied according to the schedule (16) and (17). Hence, the situation at the start of $t=1$ is identical for each run under the various indexation schedules. At the start of $t=1$, the process $z_{t}$ is rescaled to unity $\left(z_{1}=1\right)$ and both the nominal pension rights and the assets accumulated through voluntary savings of all the individuals are rescaled by the same factor. Using (11) and (12), we can then compute total pension liabilities at the start of $t=1$. Because welfare depends on the size of the buffer after the initialisation period in the simulation run, we reset the stock of pension fund assets such that the funding ratio at the start of $t=1$ equals the desired initial funding ratio, which is

\footnotetext{
12 Meaningful simulations of the very long run with permanent ageing require that the retirement age follows the increase in life expectancy and that accumulated pensions rights are properly adjusted (see also below). Otherwise, pension funds will suffer from a permanent state of underfunding, workers will face ever-rising contribution rates or retirees will suffer from continuing erosion of the purchasing power of their pensions. Hence, the consequences of the ageing process may be even worse for pension funds than simulated here if ageing is assumed to be permanent. There is no agreement on the question of this permanency, although Oeppen and Vaupel (2002) demonstrate that the assumed limits to life expectancy have so far always proven wrong.
} 


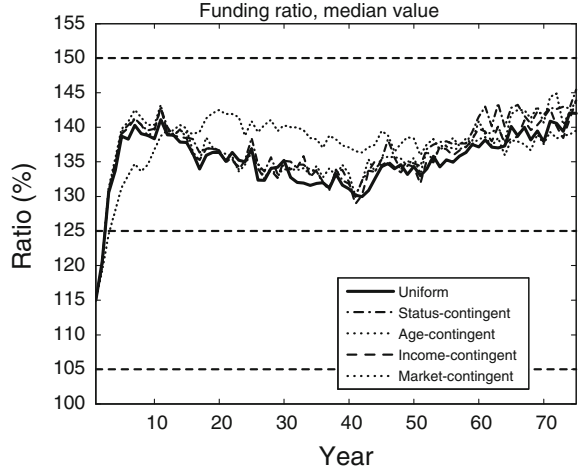

(a) Median trend

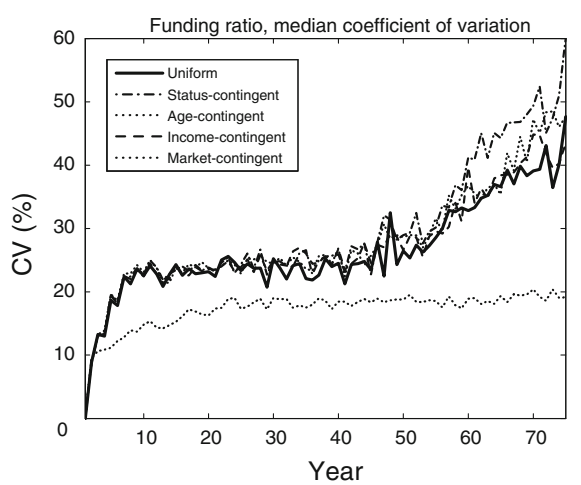

(b) Coefficient of variation

Fig. 2 Funding ratio. Notes: The figure depicts for each of the first 75 years into the simulation run (after the initialisation phase) the median value and the median coefficient of variation across the simulation runs

1.15 in the benchmark case. ${ }^{13}$ (Consistent with (17), we set $\kappa_{1}=\frac{2}{3}\left(\frac{1.15-1.05}{1.25-1.05}\right)=\frac{1}{3}$.) Hence, the assets and liabilities of the pension fund at the start of $t=1$ are identical across the various indexation schedules. The starting assets of the newborns are zero at the start of $t=1, a_{i, 1,1}=0$.

\section{Results}

\subsection{Benchmark Analysis}

Panel a of Fig. 2 shows the median funding ratio for the various indexation schemes under consideration. ${ }^{14}$ In all instances, the median funding ratio is kept well within the $\left[\xi^{m}, \xi^{u}\right]$ interval and, after the initial couple of years, when the funding ratio restores quickly from a situation of underfunding, there is no clear trend visible. The dispersion in the median funding ratios across the various indexation schemes is rather small. This is also the case for the coefficient of variation of the funding ratio, which is defined as half the interquartile range over its median. It shows an upward trend. The exception is the case of market-contingent indexation, where the volatility of the funding ratio is clearly lower and the upward trend is much weaker (see panel b of Fig. 2).

Table 2 presents summary statistics for the various indexation policies. The statistics associated with the funding ratio and the policy instruments are rather similar across the various cases, except for the case of market-contingent indexation. While the correlations between the values of the assets and the liabilities are between 65 and $70 \%$ for the other cases, under market-contingent indexation this correlation is

\footnotetext{
13 Initial assets $A_{0}$ are 1.13 times aggregate income in the economy. This is quite comparable with second-pillar pension assets in the Netherlands which are on the order of 120-130\% of GDP.

14 We report the median rather than the average funding ratio, because the former is not affected by the few extreme outcomes in our simulations.
} 
Table 2 Funding ratio properties, benchmark case

\begin{tabular}{|c|c|c|c|c|c|}
\hline$\%$ & Uniform & $\begin{array}{l}\text { Status } \\
\text { contingent }\end{array}$ & $\begin{array}{l}\text { Age } \\
\text { contingent }\end{array}$ & $\begin{array}{l}\text { Income } \\
\text { contingent }\end{array}$ & $\begin{array}{l}\text { Market } \\
\text { contingent }\end{array}$ \\
\hline \multicolumn{6}{|c|}{ Funding ratio volatility ( $C V=$ coefficient of variation $)$} \\
\hline Median CV & 26.534 & 29.471 & 28.124 & 27.415 & 17.153 \\
\hline Median CV, assets & 35.254 & 35.579 & 35.866 & 35.337 & 29.684 \\
\hline Median CV, liabilities & 47.904 & 49.534 & 49.984 & 48.650 & 36.928 \\
\hline Assets-liabilities correlation & 67.051 & 66.925 & 63.540 & 68.963 & 90.723 \\
\hline \multicolumn{6}{|c|}{ Probability of a funding ratio below a given threshold } \\
\hline Below $\xi^{l}$ & 16.991 & 16.917 & 17.131 & 17.021 & 13.000 \\
\hline Below $\xi^{m}$ & 38.652 & 37.597 & 37.669 & 38.200 & 34.771 \\
\hline Below $\xi^{u}$ & 62.961 & 61.343 & 61.547 & 62.117 & 64.051 \\
\hline \multicolumn{6}{|c|}{ Probability of a change in the indexation and contribution rates (with a ratio below $\xi^{m}$ ) } \\
\hline Only indexation rate & 3.839 & 4.263 & 4.371 & 4.192 & 5.456 \\
\hline Both rates is enough & 34.176 & 32.723 & 32.683 & 33.365 & 28.183 \\
\hline Both rates is not enough & 0.637 & 0.612 & 0.616 & 0.643 & 1.132 \\
\hline \multicolumn{6}{|c|}{ Average policy parameters (standard deviation in parentheses) } \\
\hline Contribution rate $\theta_{t}^{S}$ & $\begin{array}{l}19.554 \\
(5.917)\end{array}$ & $\begin{array}{l}19.493 \\
(5.923)\end{array}$ & $\begin{array}{l}19.360 \\
(5.940)\end{array}$ & $\begin{array}{l}19.459 \\
(5.930)\end{array}$ & $\begin{array}{l}18.830 \\
(5.959)\end{array}$ \\
\hline Indexation rate $\kappa_{t}$ & $\begin{array}{l}62.722 \\
(61.344)\end{array}$ & $\begin{array}{l}64.425 \\
(61.400)\end{array}$ & $\begin{array}{l}66.035 \\
(61.502)\end{array}$ & $\begin{array}{l}64.457 \\
(61.424)\end{array}$ & $\begin{array}{l}64.410 \\
(9.694)\end{array}$ \\
\hline \multicolumn{6}{|c|}{$\%$ Welfare comparison relative to uniform indexation } \\
\hline PER & - & 22.014 & 25.353 & 14.491 & 99.970 \\
\hline $\mathrm{EV}$ & - & -0.471 & -0.160 & -0.489 & 0.394 \\
\hline
\end{tabular}

Statistics are based on all simulation runs, excluding the initialisation phase. The columns report the cases of uniform indexation and the alternative indexation arrangements. Further, $C V=$ coefficient of variation, $P E R=$ percentage of those alive at $t=1$ in favour of an alternative to uniform indexation, $E V=$ equivalent variation, measured as the percentage increase in initial income under uniform indexation of those alive at $t=1$ and the future born that makes aggregate welfare equal to that under the alternative. Hence, a negative value indicates that aggregate welfare under the alternative is lower

over $90 \%$, implying a substantially smaller mismatch between the values of the assets and the liabilities, which explains the lower funding ratio volatility for this alternative as well as the lower probability of a funding ratio below $\xi^{l}=105 \%$ (13\% versus around $17 \%$ for the other alternatives). Nevertheless, this still is substantially more frequent than the $2.5 \%$ of time that was foreseen by DNB, but it may quite well be in line with the frequency of underfunding that we have observed over the past decade in the Netherlands. The likelihood that the funding ratio is below $\xi^{m}=125 \%$ and a long-term restoration plan is needed is always in the range 34-39\%. This likelihood equals the probability that one or more of the policy instruments needs to be altered. The likelihood that the indexation rate needs to be adjusted is around the range of $3.5-6 \%$. The likelihood that both the indexation rate and the contribution rate have to be altered and that these adjustments are sufficient is in the range of $28-35 \%$. Finally, the likelihood that these adjustments are jointly insufficient and pension rights need to be cut is in the range of $0.6-1.2 \%$.

We observe that the average indexation rate is in the range of $62-65 \%$, implying an average indexation of $1.85-1.95 \%$ of the stock of nominal rights, which is only slightly below what is sufficient to preserve the purchasing power of the pensions. Figure 3 shows the average (remaining for those alive at $t=1$ ) life-cycle indexation 


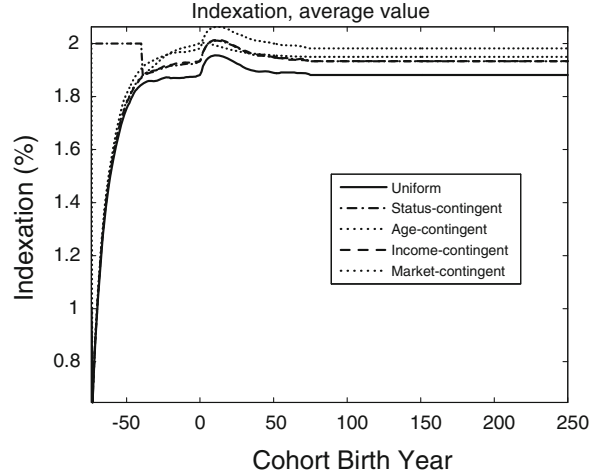

(a) Average

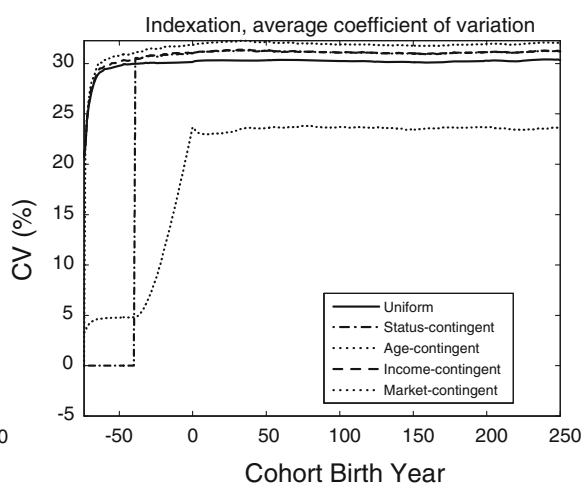

(b) Coefficient of variation

Fig. 3 Lifetime indexation (\% accumulated rights). Notes The figure depicts for each cohort the average indexation rate over the years of its life

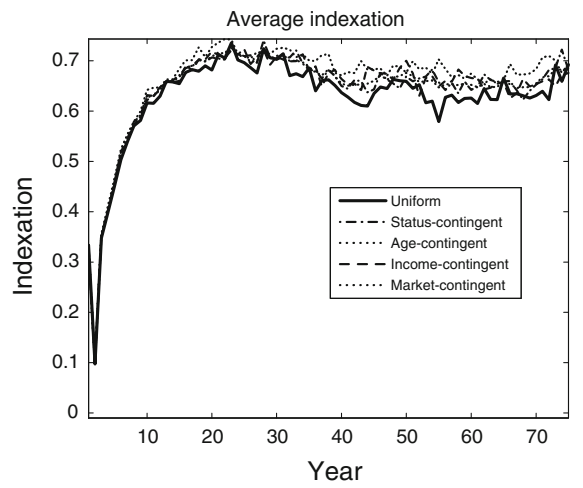

(a) Indexation rate

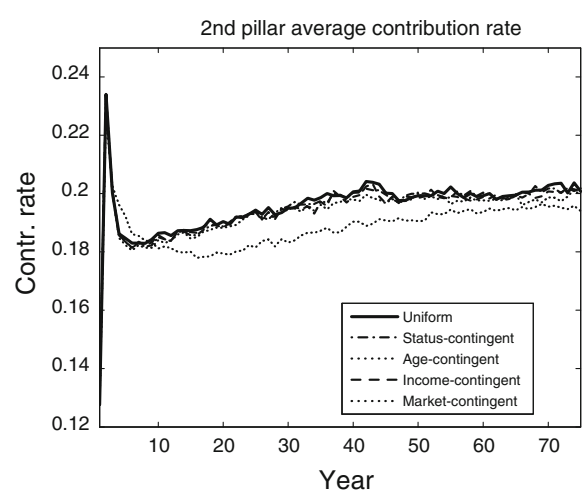

(b) Contribution rate

Fig. 4 Average policy parameters. Notes The figure depicts for each of the first 75 years into the simulation run (after the initialisation phase) the average values of the policy parameters across the simulation runs

for each cohort in our simulations. Due to the starting position of the funding ratio below $\xi^{m}$ and, hence, the low initial indexation, except in the case of status-contingent indexation, the older generations alive at $t=1$ experience low average indexation over their remaining lifetime. The younger generations, and those born after $t=1$, enjoy average lifetime indexation slightly below $2 \%$. The average contribution rate is in the range of $18-20 \%$ for the various cases under consideration (Fig. 4, panel b), which is about fifty percent above the starting value of the second-pillar contribution rate. Hence, the almost entire preservation of the purchasing power of the pensions while the population is ageing results in a substantially higher average contribution rate than at the start of the simulation run. This result confirms the message of the Goudswaard-Report (Goudswaard et al. 2010) that in absence of additional measures 
to preserve the sustainability of the Dutch second pillar, contributions need to increase to potentially unacceptable levels over the coming decades. ${ }^{15}$

Table 2 also reports a welfare comparison of alternative indexation schemes with the benchmark of uniform indexation. For all alternatives, except for marketcontingent indexation, uniform indexation is preferred by a majority of those alive in period 1 (as indicated by $P E R<50$ ). Also, when measured by the aggregate equivalent variation $E V$, uniform indexation outperforms all these alternatives, although the outperformance is on average relatively small. The value of $-0.471 \%$ for $E V$ under status-contingent indexation should be interpreted as follows. Status-contingent indexation produces the same welfare as uniform indexation if under status-contingent indexation each generation alive at $t=1$ gets 0.00471 extra in resources (or $0.471 \%$ of their expected initial income), since the income process is normalised to unity at $t=1$, newborns at $t=2$ get $0.00471 *\left(1+g_{2}\right)$ extra, the newborns at $t=3$ get $0.00471 *\left(1+g_{2}\right)\left(1+g_{3}\right)$ extra, etc. Market-contingent indexation is the only alternative that performs better than uniform indexation. Of those alive at $t=1$, virtually everyone benefits from market-contingent indexation. The aggregate welfare improvement as measured by an $E V$ of $0.394 \%$ is rather limited.

Figure 5 reports the welfare consequences for different cohort-skill combinations of replacing uniform indexation with one of its alternatives. Points above the horizontal axis indicate a welfare gain compared with uniform indexation, and vice versa for points below the horizontal axis. Considering the overall effect of a switch away from uniform indexation, we see that those who are retired at $t=1$ benefit on average substantially (in the range of $1-3 \%$ of period $t=1$ income) under any of the alternatives. Whenever the funding ratio is below $\xi^{m}$, average indexation falls short of its target level. While under uniform indexation this shortfall is equal across generations, under the alternatives the shortfall of the younger generations is larger than for the retired. Given that the initial funding ratio is below $\xi^{m}$ and that the ageing process puts systematic downward pressure on the funding ratio, indexation of the younger generations under the alternatives to uniform indexation is systematically lower than indexation of the retirees. The exception is market-contingent indexation, which is not subject to a rescaling function. Obviously the benefit is lower for retirees from the lower skill classes because the second-pillar benefits are relatively less important as a source of income. A benign feature of market-contingent indexation is that the welfare gain of the initial retirees is not achieved at the cost of losses for the younger generations at $t=1$ and the future born. Under the other alternatives, these groups lose out and pay for the benefit enjoyed by the retired.

By calculating $E V_{i, j, 1}^{\text {no shocks }}$ and $E V_{i, 1, t}^{\text {no shocks }}$ when the shocks are absent and subtracting those values from the "overall" effects $E V_{i, j, 1}$ and $E V_{i, 1, t}$, we obtain the

\footnotetext{
15 It is of interest to compare the projected increase in the contribution rate with that computed in the "Appendix" to the Goudswaard-Report (Goudswaard et al. 2010). The Report takes 2009 as the initial year of its simulation and assumes that the initial funding ratio is $105 \%$. Based on an average nominal portfolio return of $5 \%$, the contribution rate as a share of total salary rises from $12.7 \%$ in 2009 to $17.2 \%$ in 2050 (with a peak of $19.4 \%$ in 2025). The increase in the contribution rate is proportionally somewhat less than in our model, in which contribution rates are expressed in terms of income above franchise. The difference is mostly explained by the fact that the return on the pension portfolio is slightly lower in our case $(4.5 \%$ instead of 5\%), despite the lower initial funding ratio in the Goudswaard-Report.
} 

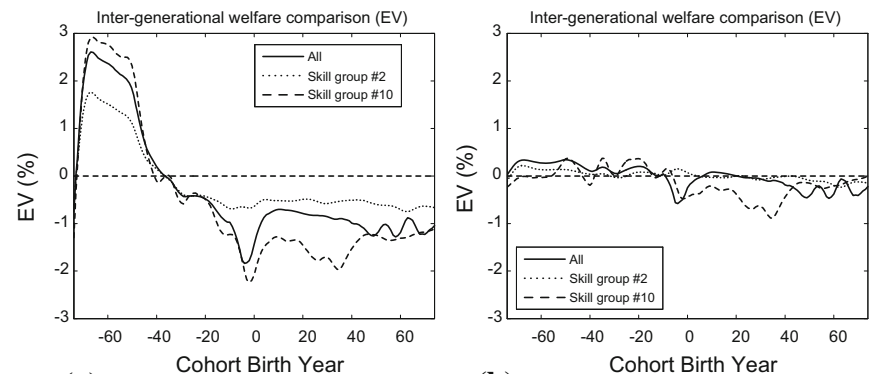

(a) Status-contingent, overall effect

(b) Status-contingent, risk sharing effect
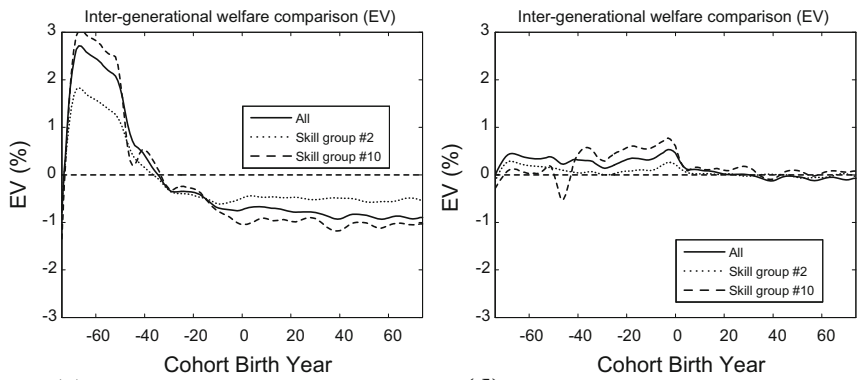

(c) Age-contingent, overall effect

(d) Age-contingent, risk sharing effect

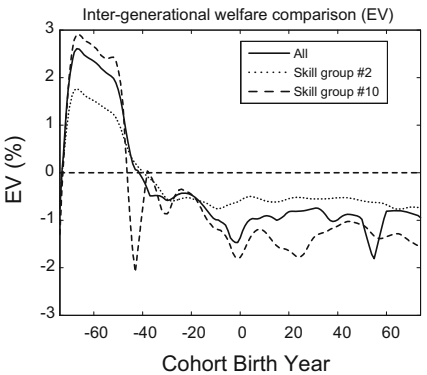

(e) Income-contingent, overall effect
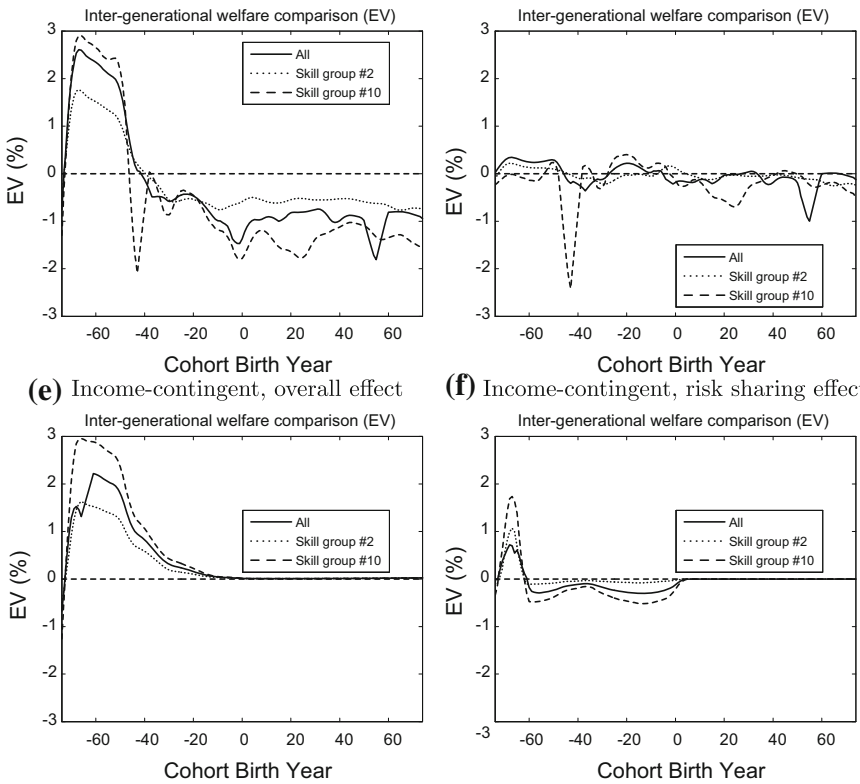

(f) Income-contingent, risk sharing effect

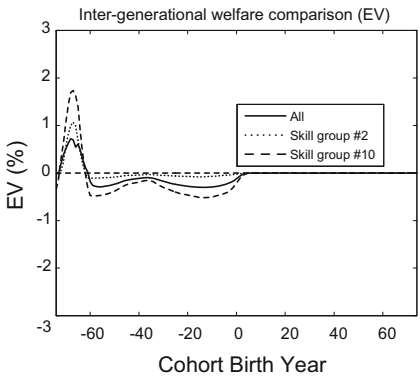

(g) Market-contingent, overall effect

(h) Market-contingent, risk sharing effect

Fig. 5 Welfare comparison (EV). Notes Equivalent variation $(E V)$ for specific groups, as characterised by birth year and skill level. We measure $E V$ as the percentage increase in initial income under uniform indexation that makes aggregate welfare equal to that under the alternative. Hence, a negative value indicates that aggregate welfare under the alternative is lower. We depict the overall welfare effect and the component that is due to risk sharing only 
equivalent variations that are purely attributable to the presence of the shocks. Hence, these are the gains (or losses, if negative) from better (worse) risk sharing under the alternative to uniform indexation. The risk-sharing effects are relatively small compared to the overall effects, implying that, except under market-contingent indexation, the overall effects are dominated by systematic redistributions from workers and future borns towards those that are retired at $t=1$.

\subsection{Robustness Analysis: Varying the Institutional Features}

This subsection varies some of the pension fund's institutional features. To save space, we report the tables and figures with the detailed results in the online appendix. Under the first variant, the second-pillar contribution rate is always kept fixed at its initial level, i.e. $\theta_{t}^{S}=\theta_{1}^{S}$ for all $t$. Hence, all the action needed to stabilise the funding ratio takes place via adjustment of the indexation rate or through a reduction in the nominal rights when necessary. The volatility in the indexation rate is higher than before, although not much except in the case of market-contingent indexation. In addition, the correlation between the assets and the liabilities becomes higher, thereby resulting in a less volatile funding ratio. Interestingly, the probability of underfunding under market-contingent indexation is now higher than under any alternative indexation scheme, rather than lower as in the benchmark analysis. Importantly, and not surprising, with the contribution rate not being allowed to rise in response to the population ageing, the average indexation rate is substantially lower than under the benchmark case. Under market-contingent indexation, the average indexation rate is even less than half its original value. Hence, retirees will be confronted with a gradual decline in the purchasing power of their second-pillar benefits as they grow older.

Second, we consider a lower initial funding ratio of $105 \%$ and a higher initial funding ratio of $125 \%$ instead of the benchmark value of $115 \%$. This is a relevant variation, because we have seen recently that, as a result of the turbulence in the financial markets, funding ratios of Dutch pension funds can vary substantially over relatively short periods of time. Hence, the starting conditions can change rather dramatically over a short time interval. Most of our earlier results are preserved when we change the initial funding ratio. However, not surprisingly, with a lower initial funding ratio of $105 \%$, the likelihood of underfunding and the average contribution rate become slightly higher, while the average indexation rate becomes slightly lower. The opposite occurs when the initial funding ratio is set at $125 \%$.

Finally, we vary the portfolio composition of the fund's assets. Our benchmark assumed equal portfolio shares of bonds and equities. We consider a low equities share of $25 \%$ and a high equities share of $75 \%$. On the one hand, the recent crisis has increased public awareness of the risks associated with funded pensions, which may force fund managers to scale back the riskiness of their portfolios. There has been some movement into this direction by Dutch pension funds, although this may also be the result of the need to reduce the risk of further decreases in the funding ratio from levels that are already low. On the other hand, with rising life expectancy and pension contributions reaching the limits of what is reasonably acceptable, the affordability of a decent (expected) pension outcome requires pension funds to invest 
more heavily in equities. Not surprisingly, with a lower share of pension portfolios invested in equities, the volatility of the funding ratio is lower. The opposite is the case when the equity share is raised relative to the benchmark share. An increase in the equities share has two opposite effects on the chances of underfunding (i.e., a funding ratio below 105\%) and a cut in nominal rights. On the one hand the higher volatility of the funding ratio raises those chances, while on the other hand the higher average portfolio return reduces those chances. We see that a change in the equities share gives rise to non-monotonicities. Both the fall and the rise in the equities share relative to the benchmark reduce the chances of underfunding, but raise the likelihoods of nominal rights cuts (except for market-contingent indexation when the equities share is raised).

As far as the welfare consequences of our variations are concerned, in all instances the aggregate welfare effects as measured by the equivalent variation are small, while we consistently find support only for market-contingent indexation.

\subsection{Robustness Analysis: Varying the Characteristics of Equity Shocks}

Forecasts about future equity returns are particularly difficult to make, especially under the current economic circumstances. Moreover, the Don et al. (2009) "Parameters Commission" failed to agree on the expected equity return that the Dutch pension funds should use when calculating the contribution rate. Hence, it is important to investigate the sensitivity of our results for different assumptions about the equity process. Again, we report the results in the online appendix. First, compared to the benchmark, we consider both a lower average equity return of $4 \%$ and a higher one of $8 \%$. We find that a lower average equity return produces a less volatile funding ratio and, not surprisingly, a higher average contribution rate and a substantially (23-24\% percentage points) lower average indexation rate than under the benchmark calibration. The opposite occurs when the average equity return is raised. While qualitatively the effects of a change in the average equity return go into the anticipated direction, quantitatively they are rather limited. Because the policy parameter settings depend (primarily) on the funding ratio and the policy rule is aimed at limiting the movements in the funding ratio, this may explain the limited magnitude of the effects.

Second, we vary the volatility of the equity shock. The benchmark estimate of the standard deviation is 0.143 (see Table 4(b) in the "Appendix"). Here, we consider a $50 \%$ lower standard deviation of 0.0715 and a $50 \%$ higher one of 0.2145 , while keeping all the other VAR estimates fixed. A lower volatility of the equity shocks produces a higher correlation of assets and liabilities and, hence, a lower volatility of the funding ratio and a lower probability of underfunding. The opposite effects (except for the assets-liabilities correlation under market-contingent indexation) result from imposing a higher volatility of the equity shock.

As far as the welfare consequences of our variations are concerned, in all instances the aggregate welfare effects of a switch away from uniform indexation as measured by the equivalent variation $E V$ are of the same sign and order of manitude as under the benchmark and thus rather small. Again the younger workers and the future born pay for the benefit that the elderly at $t=1$ enjoy. 


\subsection{Sensitivity Analysis: Raising the Retirement Age}

An increase in the retirement age is usually put forward as one of the main options to increase the financial sustainability of the Dutch second-pillar pension system. In our model, life expectancy at birth rises from 78.7 years for those born at time $t=1$ to 83.0 years for those born at time $t=41$, after which it remains stable because we assume no further growth in the survival probabilities. Our simulations up to now have been done under the assumption that the retirement age remains constant. We will now explore how our benchmark results are affected if we let the retirement age gradually increase, such that the approximate 1:2 ratio of average retirement length relative to average work life length is preserved. Concretely, this implies that we raise the retirement age at three moments, namely from 65 to 66 years at $t=11$, from 66 to 67 years at $t=26$ and, finally, from 67 to 68 years at time $t=41$. After $t=41$, the retirement age is kept fixed at 68 years. To aim at the same replacement rate after a full working life under the new life expectancy, whenever we raise the retirement age from $R^{\text {old }}$ to $R^{\text {new }}=R^{\text {old }}+1$, we also reduce the accrual rate $\mu$, from $\mu^{\text {old }}$ to $\mu^{\text {new }}=\mu^{\text {old }}\left(R^{\text {old }} / R^{\text {new }}\right)$. We assume that existing rights remain untouched. Hence, older workers accumulate pension at a slower pace for only a relatively short period. For example, someone who is 60 years at $t=11$, will accumulate pension rights for the next 6 years at a rate of $\mu^{\text {new }}$. Obviously, given that $\mu^{\text {new }}=\mu^{\text {old }}(40 / 41)$,

Table 3 Funding ratio properties, varying retirement age

\begin{tabular}{|c|c|c|c|c|c|}
\hline$\%$ & Uniform & $\begin{array}{l}\text { Status } \\
\text { contingent }\end{array}$ & $\begin{array}{l}\text { Age } \\
\text { contingent }\end{array}$ & $\begin{array}{l}\text { Income } \\
\text { contingent }\end{array}$ & $\begin{array}{l}\text { Market } \\
\text { contingent }\end{array}$ \\
\hline \multicolumn{6}{|c|}{ Funding ratio volatility ( $C V=$ coefficient of variation $)$} \\
\hline Median CV & 24.942 & 27.201 & 27.715 & 27.596 & 17.042 \\
\hline Median CV, assets & 35.220 & 35.431 & 35.652 & 35.794 & 29.614 \\
\hline Median CV, liabilities & 47.221 & 48.631 & 49.420 & 48.278 & 36.823 \\
\hline Assets-liabilities correlation & 65.676 & 67.307 & 65.056 & 68.558 & 90.947 \\
\hline \multicolumn{6}{|c|}{ Probability of a funding ratio below a given threshold } \\
\hline Below $\xi^{l}$ & 16.839 & 16.736 & 16.892 & 16.685 & 12.941 \\
\hline Below $\xi^{m}$ & 38.721 & 38.023 & 37.468 & 37.860 & 32.271 \\
\hline Below $\xi^{u}$ & 63.596 & 62.251 & 61.571 & 61.872 & 61.943 \\
\hline \multicolumn{6}{|c|}{ Probability of a change in the indexation and contribution rates (with a ratio below $\xi^{m}$ ) } \\
\hline Only indexation rate & 3.869 & 4.371 & 4.391 & 4.356 & 5.571 \\
\hline Both rates is enough & 34.204 & 33.033 & 32.444 & 32.875 & 28.012 \\
\hline Both rates is not enough & 0.648 & 0.619 & 0.633 & 0.629 & 1.045 \\
\hline \multicolumn{6}{|c|}{ Average policy parameters (standard deviation in parentheses) } \\
\hline Contribution rate $\theta_{t}^{S}$ & $\begin{array}{l}19.626 \\
(5.905)\end{array}$ & $\begin{array}{l}19.570 \\
(5.910)\end{array}$ & $\begin{array}{l}19.339 \\
(5.941)\end{array}$ & $\begin{array}{l}19.457 \\
(5.931)\end{array}$ & $\begin{array}{l}18.820 \\
(5.954)\end{array}$ \\
\hline Indexation rate $\kappa_{t}$ & $\begin{array}{l}65.520 \\
(70.918)\end{array}$ & $\begin{array}{l}69.607 \\
(73.787)\end{array}$ & $\begin{array}{l}70.793 \\
(73.283)\end{array}$ & $\begin{array}{l}68.579 \\
(72.987)\end{array}$ & $\begin{array}{l}70.131 \\
(15.796)\end{array}$ \\
\hline \multicolumn{6}{|c|}{$\%$ Welfare comparison relative to uniform indexation } \\
\hline$P E R$ & - & 20.410 & 20.410 & 20.410 & 99.957 \\
\hline$E V$ & - & -0.338 & -0.140 & -0.325 & 0.562 \\
\hline
\end{tabular}

The retirement age is gradually raised from 65 to 66 years at $t=11$, to 67 at $t=26$ and to 68 at $t=41$. Further, see notes to Table 2 
this person will retire with a higher replacement rate than under the old retirement age. Not surprisingly, the numerical outcomes reported in Table 3 are rather similar to those under the benchmark. This is the case for the behaviour of the pension buffer and the frequency with which long-term and short-term restoration plans need to be implemented. Also the average values of the policy parameters are similar to those under the benchmark. The average contribution rates remain virtually the same, while average indexation rates are only 3-6\% points higher than under the benchmark. The aggregate welfare effects of a switch away from uniform indexation remain rather small, while retirees continue to benefit from such a switch at the cost of the workers. The magnitudes of the intergenerational welfare shifts remain of the same orders of magnitude as before. Overall, these results show that, in the face of an increase in the retirement age in response to rising life expectancy, reducing the accumulation rate of pension rights without touching existing rights will only have limited effect on the sustainability of the second pillar. ${ }^{16}$

This finding sheds light on the current discussion about the adjustment of the second pillar in the Netherlands. While there is general agreement that with its current generosity and the unwillingness to substantially raise contribution rates the system becomes unsustainable at current benefit levels, there is disagreement as to what extent existing pension rights should be protected. Our finding that a mere slowdown in the accumulation of new pension rights fails to improve the system's sustainability in response to ageing demonstrates that existing pension rights would need to be reduced to ensure a decent pension for future retirees. This would imply a relatively substantial contribution from older workers and current retirees to ensure the system's sustainability.

\section{Conclusions}

We have analysed the consequences of differentiating the indexation of pension rights to nominal price and wage inflation across groups of participants in a funded pension system like that in the Netherlands. Our analysis was based on stochastic simulations of a small-open economy overlapping-generations model subject to demographic, economic and financial shocks. We have compared the usual Dutch practice of uniform indexation across all participants, with status-contingent indexation, which protects retirement benefits against price inflation, age-contingent, income-contingent and market-contingent indexation. Pension buffers behave rather similarly under most alternatives, both in terms of their median and volatility. This may not be so surprising given that the policies that regulate the value of the buffers are identical across the various scenarios. Only under market-contingent indexation, is buffer volatility markedly lower than in the other cases. At the aggregate level, as measured by the equivalent variation for all groups together, uniform indexation tends to perform better than most of the alternatives. Again, market-contingent indexation is the exception. However, the differences among the alternatives in terms of compensating initial resources are relatively small, though. The initial retirees benefit from a shift away from uniform

16 Obviously, if the accrual rate of pension rights were to be kept unchanged, sustainability would be even weaker. 
indexation. Except under market-contingent indexation, the workers and the future born are net payers for such a shift. Moreover, the group-specific welfare effects tend to be almost entirely redistributional. A shift to market-contingent indexation benefits the initially retired without hurting other age groups. Hence, this alternative provides a particularly interesting case for further study.

There is a growing discussion in the Netherlands about the benefits of differentiating pension fund policies across groups of participants. Differentiation can take place along a variety of dimensions, in particular, in terms in pension contributions, the accrual rate of the pension rights, the asset portfolios held by fund participants and indexation of pension rights. Our results suggest that for this latter form of differentiation to produce aggregate benefits a careful design of the contingencies in the indexation rule is necessary, otherwise the aggregate benefits will be negative. Nevertheless, one should be careful not to draw premature conclusions. The reason is that we have essentially focused on shifts in indexation adjustment among groups of fund participants, without assuming any compensation in terms of higher expected indexation for the groups that take on more risk. If it is possible to provide such compensation (mostly to the young at the cost of the old generations), one might find more schedules that make (almost) everyone better off than under uniform indexation. Such schedules would necessarily be even more complicated than the schedules studied in this paper and the welfare consequences for the various groups would need to be carefully investigated, before implementing a switch away from uniform indexation. Moreover, it would be a major challenge to clearly communicate how such alternatives operate. Hence, for several reasons their practical applicability is not straightforward and we leave the investigation of such schedules as an avenue for further research.

We found that an increase in the retirement age without touching the existing pension rights leaves our main findings unaffected. Realistically speaking, an increase in the retirement age will be unavoidable with rising life expectancy. However, the increase needs to be accompanied by an adjustment in the value of the existing pension rights, such that current older workers and retirees finance a larger share of the longer duration of their own pension benefits. Otherwise, as our simulations have shown, pension contribution rates need to increase drastically from their current levels. The resulting upward pressure on the total labour costs will reduce labour demand and become unaffordable by firms that are under increasingly competitive pressure from foreign firms operating in an environment with less generous pension arrangements. The alternative to not raising contribution rates would be low indexation of pension rights for a long time, which would gradually erode the real value of the pension benefits.

\section{Appendix: Estimation and Calibration of the Shocks}

\section{Growth Rate of Newborn Cohort}

Each demographic shock is distributed independently of all other shocks. The growth rate $n_{t}$ of the newborn cohort depends on deterministic and random components: 


$$
n_{t}=n+\epsilon_{t}^{n}
$$

with $n$ the mean and $\epsilon_{t}^{n}$ the innovation at time $t$, which follows an AR(1) process with parameter $\varphi$ :

$$
\epsilon_{t}^{n}=\varphi \epsilon_{t-1}^{n}+\eta_{t}^{n}, \quad \eta_{t}^{n \sim} N\left(0, \sigma_{n}^{2}\right)
$$

We estimate this model from data on the relative variation in the number of births in the Netherlands (source is Human Mortality Database 2009.) We find $n=1.0021$, $\phi=-0.0624, \sigma_{n}=0.0492$.

\section{Survival Probabilities}

We simulate the cohort survival probabilities according to:

$$
\begin{aligned}
& \ln \left(1-\psi_{j, t-j+1}\right)=\ln \left(1-\psi_{j, t-j}\right)+\tau_{j}\left(\chi+\epsilon_{t-j+1}^{\psi}\right), \\
& \epsilon_{t-j+1}^{\psi} \sim N\left(0, \sigma_{\psi}^{2}\right), \quad j=1, \ldots, D
\end{aligned}
$$

with $\tau_{j}$ an age-dependent coefficient, $\chi$ a constant growth factor (to describe the historical trend increase in survival probabilities) and $\epsilon_{t-j+1}^{\psi}$ an innovation at time $t-j+1$ that follows an i.i.d. process with variance $\sigma_{\psi}^{2}$. The parameters $\tau_{j}$ and $\chi$ and the shock process $\epsilon_{t-j+1}^{\psi}$ need to be estimated. This would require cohort life tables, which are incomplete for recent cohorts. Using easily available period life tables, however, leads to an over-estimation of mortality because of the well-documented downward trend in mortality.

To correctly estimate mortality, we follow the Lee-Carter model (1992) and collect from the Human Mortality Database (2009) Dutch period life tables from 1906 to 2005. These contain the total population on a year-by-year basis from ages 0-110. In these tables, $\psi_{j, t}^{p}$ is the population probability of surviving year $t$ for individuals aged $j$. These individuals thus have survived year $t-1$. (Hence, probability $\psi_{j, t}^{p}$ should be distinguished from the cohort survival probability $\psi_{j, t-j+1}$.) To distinguish the trend from fluctuations, we estimate with singular value decomposition the parameters of the Lee-Carter model:

$$
\ln \left(1-\psi_{j, t}^{p}\right)=\alpha_{j}+\tau_{j} \chi_{t}+\eta_{t}^{\psi}
$$

where $\alpha_{j}$ and $\tau_{j}$ are age-varying parameters, $\chi_{t}$ is a time-varying vector and $\eta_{t}^{\psi}$ is a random disturbance distributed as $N\left(0, \tilde{\sigma}_{\psi}^{2}\right)$. Lee and Carter (1992) point out that the parameterization is not unique. Therefore, we choose the one fulfilling their suggested restrictions: 


$$
\left\{\begin{array}{c}
\sum_{t=1}^{T} \chi_{t}=0 \\
\sum_{j=1}^{D} \tau_{j}=1
\end{array}\right\},
$$

where $t=1, \ldots, T$ indicates the sample period. With these restrictions it is easy to see that the estimated value for $\alpha_{j}$ will be the average probability over the sample that someone dies at age $j$, when having survived up to age $j-1$. Consistent with the existing literature we assume that the mortality index $\chi_{t}$ evolves as a random walk with drift $\chi$ :

$$
\chi_{t}=\chi_{t-1}+\chi+\epsilon_{t}^{\psi}
$$

with $\epsilon_{t}^{\psi \sim} N\left(0, \sigma_{\psi}^{2}\right)$. We estimate $\hat{\chi}=-1.6733$ and $\hat{\sigma}_{\psi}=0.0957$, which implies a trend fall in the probability of dying at any age $j$, conditional on having survived up to age $j-1$. In the simulations we assume that $\hat{\chi}=0$ after year $t=40$. That is, there is no further population ageing after 40 years.

From the period life table estimates and the trend in the mortality index we calculate the cohort life tables as follows:

$$
\begin{aligned}
\ln \left(1-\psi_{j, t-j+1}\right) & =\hat{\alpha}_{j}+\hat{\tau}_{j}\left(\hat{\chi}_{t-j+1}+j \hat{\chi}\right) \\
& =\hat{\alpha}_{j}+\hat{\tau}_{j} \hat{\chi}_{t+1},
\end{aligned}
$$

where $t-j+1$ is the year of birth of the cohort.

In our simulations, the survival probabilities of the cohort born in year $t=0$ are set equal to those of the actual cohort of individuals born in 1950. Conditional survival probabilities of cohorts of age $j$ are linked over time as follows:

$$
\begin{aligned}
\ln \left(1-\psi_{j, t-j+2}\right) & =\hat{\alpha}_{j}+\hat{\tau}_{j}\left(\hat{\chi}_{t-j+2}+j \hat{\chi}\right) \\
& =\alpha_{j}+\hat{\tau}_{j}\left(\hat{\chi}_{t-j+1}+j \hat{\chi}+\hat{\chi}\right) \\
& =\alpha_{j}+\hat{\tau}_{j}\left(\hat{\chi}_{t+1}+\hat{\chi}\right) \\
& =\ln \left(1-\psi_{j, t-j+1}\right)+\hat{\tau}_{j} \hat{\chi} .
\end{aligned}
$$

Economic and Financial Shocks

We allow the shocks to the inflation rate, the nominal income growth rate, the one-year bond return and the equity return to be correlated with each other and over time. These variables follow the multivariate annual process (13) with the innovations following the VAR(1) process (14). 
Table 4 VAR(1) regression

\begin{tabular}{|c|c|c|c|c|}
\hline Variable & Inflation & Wage & Bond & Equity \\
\hline \multicolumn{5}{|c|}{ a. Deterministic coefficient estimates (matrix $\mathbf{B}$ in (14)) } \\
\hline Inflation $(-1)$ & $\begin{array}{l}0.7685 * * * \\
(0.1789)\end{array}$ & $\begin{array}{l}0.5258 * * * \\
(0.1848)\end{array}$ & $\begin{array}{l}0.0584 \\
(0.2668)\end{array}$ & $\begin{array}{l}-0.3263 \\
(2.4723)\end{array}$ \\
\hline Wage $(-1)$ & $\begin{array}{l}-0.1757 \\
(0.1828)\end{array}$ & $\begin{array}{l}0.0108 \\
(0.1888)\end{array}$ & $\begin{array}{l}0.0222 \\
(0.2726)\end{array}$ & $\begin{array}{l}-2.7298 \\
(2.5258)\end{array}$ \\
\hline Bond $(-1)$ & $\begin{array}{l}0.0670 \\
(0.0692)\end{array}$ & $\begin{array}{l}0.0479 \\
(0.0714)\end{array}$ & $\begin{array}{l}0.8700 * * * \\
(0.1032)\end{array}$ & $\begin{array}{l}0.8933 \\
(0.9560)\end{array}$ \\
\hline Equity $(-1)$ & $\begin{array}{l}-0.0062 \\
(0.0128)\end{array}$ & $\begin{array}{l}-0.0133 \\
(0.0132)\end{array}$ & $\begin{array}{l}0.0152 \\
(0.0190)\end{array}$ & $\begin{array}{l}-0.0123 \\
(0.1764)\end{array}$ \\
\hline Wald chi-squared & 58.5525 & 38.4297 & 98.2896 & 4.8642 \\
\hline$p$-value & 0.0000 & 0.0000 & 0.0000 & 0.3015 \\
\hline \multicolumn{5}{|c|}{ b. Residual covariances and correlations (\%) } \\
\hline Inflation & 0.0107 & 33.3503 & 34.8257 & -26.7663 \\
\hline Wage & 0.0037 & 0.0114 & -25.9594 & -6.7091 \\
\hline Bond & 0.0056 & -0.0043 & 0.0238 & -11.9154 \\
\hline Equity & -0.0396 & -0.0102 & -0.0263 & 2.0449 \\
\hline
\end{tabular}

Standard deviations in parentheses. $* * *$ : significant at $1 \%$. Wald chi-squared: test on the joint significance of the coefficients in each column, following a chi-squared distribution with four degrees of freedom.

Correlations in italics

The underlying data are the following time series, covering annually the period 1976-2005 (30 observations). For the economic variables (inflation rate and income growth rate), we take series of the Dutch Consumer Price Index and Dutch hourly wages (source for both series: OECD 2009). For the financial variables (bond and equity returns), we consider U.S. time series, given the wide integration of the financial market and the larger availability of data for the U.S. We take series on end-of-year public debt yields at maturity one year (source: Federal Reserve 2009) and the MSCI U.S. equity index (source: Datastream 2009). For each series we take the deviations from the historical average.

Table 4 shows the (annual-frequency) estimation of the deterministic component (panel a) and the covariances and correlations of the residuals (panel b). It is worth pointing out that only in the specification of the equity return the Wald chi-squared test on the joint significance of the coefficients does not reject the hypothesis that returns follow a purely random (white noise) process.

\section{The Bond Yield Curve}

We finally turn to the bond yield curve $\left\{r_{k, t}^{b}\right\}_{k=1}^{D}$. The interest rate at maturity $k=1$ will be set equal to the simulated short-term bond interest rate based on the VAR(1) process (14), $r_{1, t}^{b}=r_{t}^{s b}$. To describe the components of the yield curve at maturities $k=2, \ldots, D$, we focus on the rates in excess of the bond interest rate at maturity $1, \widetilde{r}_{k, t}^{b}$. Following the prevailing literature (see, e.g., Evans and Marshall 1998; Dai and Singleton 2000), we model the excess interest rates as a vector autoregressive distributed lag (VADL) process with lag 1: 


$$
\begin{aligned}
\left(\begin{array}{c}
\widetilde{r}_{2, t}^{b} \\
\widetilde{r}_{3, t}^{b} \\
\vdots \\
\widetilde{r}_{D, t}^{b}
\end{array}\right)= & \Gamma_{0}+\Gamma_{1}\left(\begin{array}{c}
\widetilde{r}_{2, t-1}^{b} \\
\widetilde{r}_{3, t-1}^{b} \\
\vdots \\
\widetilde{r}_{D, t-1}^{b}
\end{array}\right)+\Gamma_{2}\left(\begin{array}{c}
\pi_{t-1} \\
g_{t-1} \\
r_{t-1}^{s b} \\
r_{t-1}^{e}
\end{array}\right) \\
& +\left(\begin{array}{c}
\epsilon_{2, t}^{b} \\
\epsilon_{3, t}^{b} \\
\vdots \\
\epsilon_{D, t}^{b}
\end{array}\right), \text { with }\left(\begin{array}{c}
\epsilon_{2, t}^{b} \\
\epsilon_{3, t}^{b} \\
\vdots \\
\epsilon_{D, t}^{b}
\end{array}\right) \sim(\mathbf{0}, \Sigma)
\end{aligned}
$$

Each period $t$, the excess interest rate at maturity $k, \widetilde{r}_{k, t}^{b}, k \geqslant 2$, is a linear combination of deterministic and random components. The deterministic part is a function of several variables at time $t-1$ : the excess interest rates at all maturities $k \geqslant 2$ and the four macro and financial variables whose shocks follow the VAR(1) process (14). The random part is given by the innovations $\epsilon_{k, t}^{b}$, which may be correlated across maturities.

We estimate (19) using an annual time series of U.S. yield returns at maturities 2, 3, 5, 7, 10, 20 and 30 (the only observed maturities-source is Federal Reserve 2009) over the period 1976-2006. In the sample there are occasionally missing values for the yields at maturities 20 and 30 that we replace in the regression with their interpolations. The output from the estimation of (19) is available upon request. We obtain large R-squared statistics (above 0.95), slightly decreasing at longer maturities, and always reject the hypothesis that the interest rates follow a white noise process. The shocks estimated in (19) are highly correlated (usually above $80 \%$ and never below $71 \%$ ); shocks tend to be more volatile at longer maturities (with a variance ranging from 0.0003 at maturity 2 to 0.0027 at maturity 30), but they remain small compared to the variance (0.0238) of shocks to the one-year bond returns estimated in (14). Having estimated (19) for the maturities that are available, we then adopt a linear interpolation over these yields to obtain the interest rates at any discrete maturity between 1 and 30. Interest rates at maturities longer than 30 are set equal to the interest rate at maturity 30.

Actual yield returns at any maturity $k \geq 1$ are then built as the sum of the VADL(1) realisations and the realisation of the one-year bond interest rate:

$$
\left(\begin{array}{c}
r_{1, t}^{b} \\
r_{2, t}^{b} \\
r_{3, t}^{b} \\
\vdots \\
r_{D, t}^{b}
\end{array}\right)=\left(\begin{array}{c}
r_{t}^{s b} \\
r_{t}^{s b} \\
r_{t}^{s b} \\
\vdots \\
r_{t}^{s b}
\end{array}\right)+\left(\begin{array}{c}
0 \\
\widetilde{r}_{2, t}^{b} \\
\widetilde{r}_{3, t}^{b} \\
\vdots \\
\widetilde{r}_{D, t}^{b}
\end{array}\right)
$$

The average yield curve $\left\{r_{k}^{b}\right\}_{k=1}^{D}$ is given by the average yield at maturity $1, r^{s b}$, plus a second term, which is obtained from (19) using $E\left[\tilde{r}_{k, t}^{b}\right]=E\left[\tilde{r}_{k, t-1}^{b}\right]$ because of stationarity: 


$$
\left(\begin{array}{c}
r_{2}^{b} \\
r_{3}^{b} \\
\vdots \\
r_{D}^{b}
\end{array}\right)=\left(\begin{array}{c}
r^{s b} \\
r^{s b} \\
\vdots \\
r^{s b}
\end{array}\right)+\left(I-\Gamma_{1}\right)^{-1}\left(\Gamma_{0}+\Gamma_{2}\left(\begin{array}{l}
\pi \\
g \\
r^{s b} \\
r^{e}
\end{array}\right)\right)
$$

This average bond yield curve increases monotonically up to $k=30$, where it reaches an estimated interest rate of $4.26 \%$.

Open Access This article is distributed under the terms of the Creative Commons Attribution Noncommercial License which permits any noncommercial use, distribution, and reproduction in any medium, provided the original author(s) and source are credited.

\section{References}

Alessie, R., Hochguertel, S., \& van Soest, A. (2001). Household portfolios in the Netherlands. In L. Guiso, M. Haliassos, \& T. Jappelli (Eds.), Household portfolios, chapter 9. Cambridge, MA: MIT Press.

Beetsma, R. M. W. J., \& Schotman, P. C. (2001). Measuring risk attitudes in a natural experiment: Data from the television game show LINGO. Economic Journal, 111(474), 821-848.

Bodie, Z., Merton, R. C., \& Samuelson, W. F. (1992). Labor supply flexibility and portfolio choice in a life cycle model. Journal of Economic Dynamics and Control, 16(3-4), 427-449.

Bohn, H. (2001). Social security and demographic uncertainty: The risk-sharing properties of alternative policies. In J. Y. Campbell \& M. Feldstein (Eds.), Risk aspects of investment-based social security reform. Chicago: University of Chicago Press.

Bohn, H. (2006). Who bears what risk? An intergenerational perspective. In D. Blitzstein, O. S. Mitchell, \& S. P. Utkus (Eds.), Restructuring retirement risk. Oxford, UK: Oxford University Press.

Bonenkamp, J., \& Westerhout, E. W. M. T. (2010). Intergenerational risk sharing and labour supply in collective funded pension schemes with defined benefits. CPB Discusion paper, no. 151.

Brennan, M. J., \& Xia, Y. (2002). Dynamic asset allocation under inflation. Journal of Finance, 57(3), 1201-1238.

Bucciol, A., \& Beetsma, R. M. W. J. (2010). Inter- and intra-generational consequences of pension buffer policy under demographic, financial and economic shocks. CESifo Economic Studies, 56(3), 366-403.

Cui, J., De Jong, F., \& Ponds, E. (2011). Intergenerational risk sharing within funded pension schemes. Journal of Pension Economics and Finance, 10(1), 1-29.

Dai, Q., \& Singleton, K. (2000). Specification analysis of affine term structure models. Journal of Finance, 55(5), 1943-1978.

Datastream (2009). www.datastream.com.

DNB (2009). www.statistics.dnb.nl.

Don, F. J. H., Driessen, C. C. H. J., van Ewijk, C., Knot, K. H. W., \& van Popta, K. B. (2009). Advies betreffende parameters pensioenfondsen. The Hague: Ministerie van Sociale Zaken en Werkgelegenheid.

Enders, W., \& Lapan, H. E. (1982). Social security taxation and intergenerational risk sharing. International Economic Review, 23(3), 647-658.

Evans, C., \& Marshall, D. (1998). Monetary policy and the term structure of nominal interest rates: Evidence and theory. Carnegie-Rochester Conference Series on Public Policy, 49(1), 53-111.

Federal Reserve (2009). www.federalreserve.gov/releases/H15.

Gertner, R. (1993). Game shows and economic behavior: Risk taking on "card sharks". Q J Econ, 108, 507-521.

Goudswaard, K., Beetsma, R. M. W. J., Nijman, T. E., \& Schnabel, P. (2010). Een Sterke Tweede Pijler: naar een Toekomstbestendig Stelsel van Aanvullende Pensioenen. Report Commissie Toekomstbestendigheid Aanvullende Pensioenregelingen. The Hague: Ministerie van Sociale Zaken en Werkgelegenheid.

Hansen, G. D. (1993). The cyclical and secular behaviour of the labour input: Comparing efficiency units and hours worked. Journal of Applied Econometrics, 8(1), 71-80. 
Heaton, J., \& Lucas, D. (2000). Portfolio choice in the presence of background risk. Economic Journal, 110(460), 1-26.

Human Mortality Database (2009). www.mortality.org.

Hurst, E., \& Willen, P. (2007). Social security and unsecured debt. Journal of Public Economics, 91(7-8), 1273-1297.

Imrohoroglu, A. (1989). Costs of business cycles with indivisibilities and liquidity constraints. Journal of Political Economy, 97(6), 1364-1383.

Imrohoroglu, A., Imrohoroglu, S., \& Joines, D. H. (2003). Time inconsistent preferences and social security. Quarterly Journal of Economics, 118(2), 745-784.

Krebs, T. (2007). Job displacement risk and the cost of business cycles. American Economic Review, 97(3), 664-686.

Lee, R. D., \& Carter, L. R. (1992). Modeling and forecasting U.S. mortality. Journal of the American Statistical Association, 87(419), 659-671.

Merton, R. C. (1983). On the role of social security as a means for efficient risk sharing in an economy where human capital is not tradable. In Merton, R. C. (Ed.), Financial aspects of the United States pension system. Cambridge, MA: NBER Chapters.

Molenaar, R., \& Ponds, E. H. M. (2009). Differentiatie naar Leeftijd in de Financieiring van Collectieve Pensioenen. NEA Netspar Paper, no. 7.

OECD (2009). www.stats.oecd.org.

Oeppen, J., \& Vaupel, J. W. (2002). Broken limits to life expectancy. Science, 296(5570), 1029-1031.

Pelizzon, L., \& Weber, G. (2009). Efficient portfolios when housing needs change over the lifecycle. Journal of Banking and Finance, 33(11), 2110-2121.

Ponds, E. H. M. (2008). Naar meer Jong en Oud in Collectieve Pensioenen. Inaugural lecture, Tilburg University.

Teulings, C. N., \& de Vries, C. G. (2006). Generational accounting, solidarity and pension losses. De Economist, 154(1), 63-83.

van Ewijk, C., Draper, N., ter Rele, H., \& Westerhout, E. W. M. T. (2006). Ageing and the sustainability of Dutch public finances. CPB Special Publication, 61.

WIID (2008). version 2.0c, www.wider.unu.edu/research/Database/en_GB/database. 